NBER WORKING PAPER SERIES

\title{
SPECULATIVE GROWTH: HINTS FROM THE US ECONOMY
}

\author{
Ricardo Caballero \\ Emmanuel Farhi \\ Mohamad L. Hammour \\ Working Paper 10518 \\ http://www.nber.org/papers/w10518
}

\author{
NATIONAL BUREAU OF ECONOMIC RESEARCH \\ 1050 Massachusetts Avenue \\ Cambridge, MA 02138
}

May 2004

We are grateful to Björn Brügemann for outstanding research assistance and to the European Central Bank Research Department and the International Institute for Economic Studies for their hospitality. We thank Franklin Allen, Marios Angeletos, Gadi Barlevy, Olivier Blanchard, Thomas Chaney, Peter Diamond, Thomas Philippon, Frank Portier, Pietro Reichlin, Jean Tirole, Jaume Ventura and seminar participants at Boston University, CORE, DELTA, ESSIM, Harvard, IIES, MIT, the NBER EFG meetings, Northwestern, Toulouse, and Wharton for useful comments. Caballero thanks the NSF for financial support. This is an extensively revised and transformed version of NBER WP \#9831, December 2002. The views expressed herein are those of the author(s) and not necessarily those of the National Bureau of Economic Research.

(C)2004 by Ricardo Caballero, Emmanuel Farhi, and Mohamad L. Hammour. All rights reserved. Short sections of text, not to exceed two paragraphs, may be quoted without explicit permission provided that full credit, including (C) notice, is given to the source. 
Speculative Growth: Hints from the US Economy

Ricardo Caballero, Emmanuel Farhi, and Mohamad L. Hammour

NBER Working Paper No. 10518

May 2004

JEL No. D0, D9, E2, E3, G1, H3

\section{ABSTRACT}

We propose a framework for understanding recurrent historical episodes of vigorous economic expansion accompanied by extreme asset valuations, as exhibited by the U.S. in the 1990s. We interpret this phenomenon as a high-valuation equilibrium with a low effective cost of capital based on optimism about the future availability of funds for investment. The key to the sustainability of such an equilibrium is feedback from increased growth to an increase in the supply of effective funding. We show that such feedback arises naturally when an expansion comes with technological progress in the capital producing sector, when fiscal rules generate sustained fiscal surpluses, when the rest of the world has lower expansion potential, and when financial constraints are relaxed by the expansion itself. Arguably, these ingredients were all simultaneously present in the U.S. during the 1990s. We also show that such expansions can be welfare improving but they can crash. The latter is more likely if bubbles develop along the expansionary path. These (rational) bubbles can emerge even when the interest rate exceeds the rate of growth of the economy.

Ricardo J. Caballero

Department of Economics

MIT

Room E52-252a

Cambridge, MA 02142-1347

and NBER

caball@mit.edu

Emmanuel Farhi

MIT

efarhi@mit.edu

Mohamad L. Hammour

DELTA

hammour@delta.ens.fr 


\section{Introduction}

Economic history has witnessed many stark "speculative growth" episodes of extreme stock market valuations accompanied by brisk economic growth. The most notable recent experience was that of the United States in the 1990s. Figure 1a illustrates the sharp rise in the NASDAQ in the 1990s, followed by the collapse of 2000-2001. The extremes reached by valuations shown in figure $1 \mathrm{~b}$, and their collapse in the absence of obvious changes in fundamentals, are suggestive of widespread speculation. Figures 1c and 1d illustrate the growth and investment boom-and-bust that accompanied the market's gyrations ${ }^{1}$.
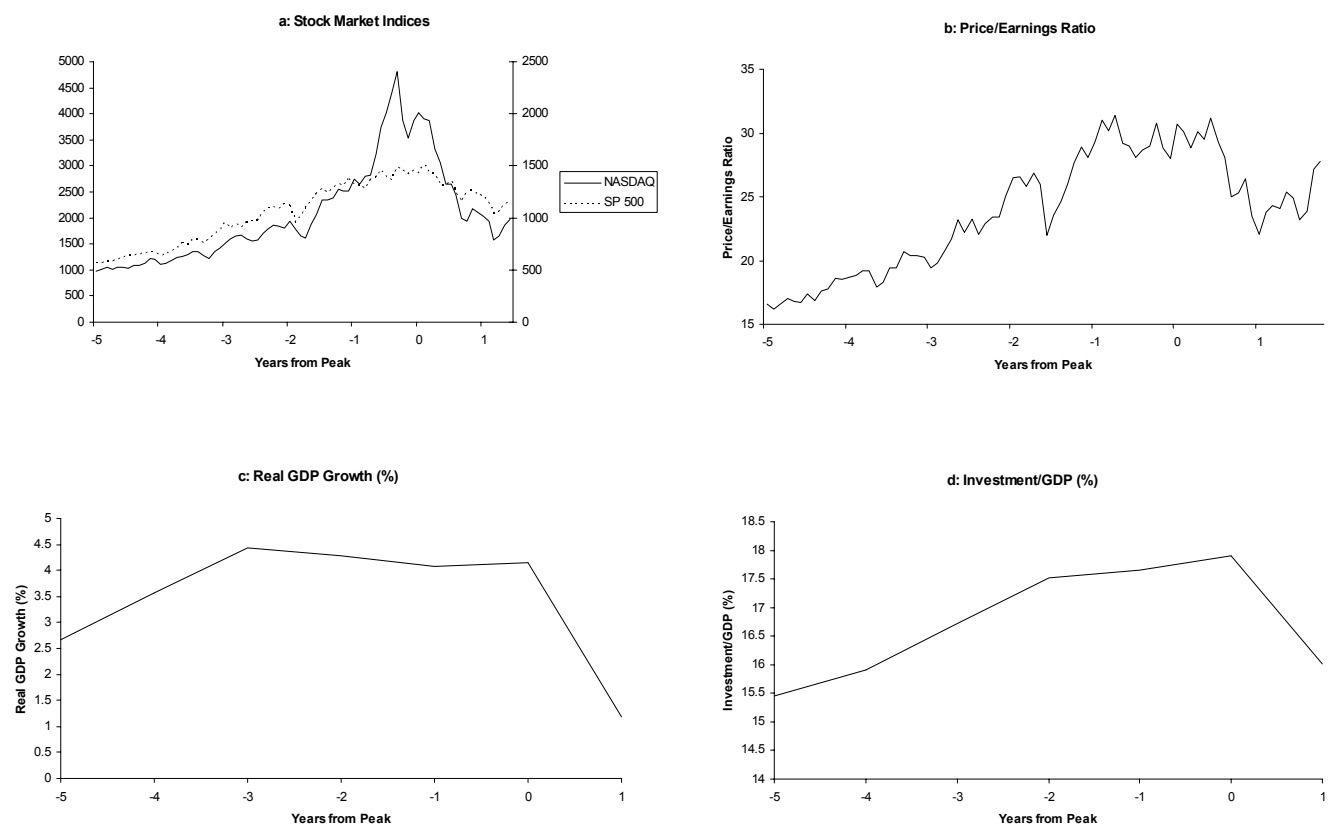

Figure 1: Speculative Growth in the US.

The nature and policy dilemmas of speculative expansions have attracted much attention (e.g., International Monetary Fund 2000, Shiller 2000, Cecchetti et al. 2000), but our formal understanding of the macroeconomic mechanisms that underlie the relation between stock market speculation and real economic activity remains quite limited. It is always possible to attribute such episodes to irrational exuberance, and indeed it is highly likely that some

\footnotetext{
${ }^{1}$ Note: Panel b: the numerator is the real (inflation-adjusted) Datastream Total Market Index; denominator is moving average over preceding ten years of real earnings corresponding to the index. Sources: Panel a: Nasdaq Composite Index from The Nasdaq Stock Market, Inc, SP 500 from Datastream. Panel b: Datastream Total Market Index for US. Panel c: Bureau of Economic Analysis (BEA). Panel d: BEA. Annual report on national accounts (CD-ROM) 1998
} 
10 years treasury rate (real and nominal)

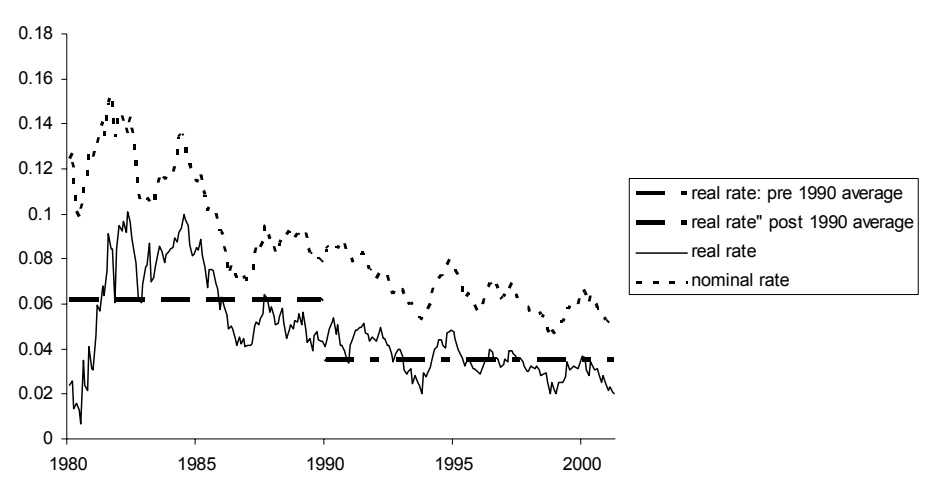

Figure 2: Long Real and Nominal Rates.

of that is invariably present. But what are the environments that facilitate these bouts of irrationality or, put differently, that facilitate the confusion of intelligent economic agents by having a rational path that is not too distant from observation?

In this paper we take an extreme approach to answering the previous question and look for rational expectations equilibria that can mimic speculative growth episodes. We take a hint from the recent U.S. episode to formulate our theory. We start from the observation that long run interest rates, and in particular the cost of capital faced by growing companies, declined throughout the 1990s. The dotted line in figure 2 illustrates the path of the 10year US Treasury-bond rate, to which we subtract the University of Michigan Inflation Expectations Index to obtain the corresponding real rate (solid line). The latter's decline during the 1990s is apparent: the difference between the average real rates for the 1980s and 1990s (dashed lines) is about 200 basis points.

Such a decline can account for a significant share of the observed rise in asset prices: The decline in the real rates implicit in US Treasury bonds alone can explain over 50 percent of the rise in broad market's valuations during the second half of the 1990s, and if one is to consider the further decline in risk premia due to increased participation in stock markets (admittedly a somewhat circular argument), then that share rises to 80 percent or more. ${ }^{23}$ Once such rise has taken place, the investment and output growth boom that followed can

\footnotetext{
${ }^{2}$ See, e.g., Vissing-Jorgensen (1999) for a model and evidence on the relation between participation and the equity premium.

${ }^{3} \mathrm{~A}$ fact that was not missed by economic commentators, and indeed was extrapolated to extreme limits by a sequel of bestsellers starting with "Dow 36,000: The new strategy for profiting from the coming rise in the stock market," by Glassman and Hassett (1999).
} 
be rationalized along standard $q$ - theory arguments.

However, the key general equilibrium question in the above story is: How are expectations of a low long-term cost of capital consistent with the high demand for savings needed to fund a high-investment equilibrium? Limited to rational explanations, this necessarily means that along the expansionary path agents expect an increase in the availability of funding to more than offset the demand for such funding. The source of this shift could be exogenous or endogenous. In our model and account of the U.S. episode we include both but highlight the latter since the crash of 2000-2001 cannot be matched by a commensurate exogenous shock. Thus the central ingredient of our model is a growth-funding feedback by which the future supply of effective funding increases as a result of the conditions created by a speculative expansion, and ends up lowering the cost of capital (the word effective is added to encompass the important decline in the price of new capital relative to consumption goods during the 1990s).

We show that speculative growth episodes can be welfare improving but they are also susceptible to crashes. The latter are more likely if bubbles develop along the expansionary path.

Of independent interest is the fact that in our environment rational bubbles exhibit more realistic features than in the standard setup. In the latter, bubbles can only appear in a "dynamically inefficient" economy, that is one whose structure is conducive to the overaccumulation of capital. Their emergence is welfare improving as they help to absorb saving away from investment and to alleviate the over-accumulation problem. However, the notion that bubbles and investment move in opposite directions is contrary to the patterns depicted in figure 1. Moreover, empirical testing of "dynamic inefficiency" has been negative. Abel et al. (1989) tested an implication of dynamic inefficiency, whether the aggregate market for assets acts as a long-term "cash sink" for investors, but found no evidence of it in OECD economies. Finally, the idea that bubbles are inherently good runs counter much of the perception of policymakers and practitioners.

In contrast, since in our model a speculative growth episode anticipates increased funding, bubbles may emerge even when the current interest exceeds the rate of growth of the economy and the corporate sector generates a surplus. And while it is still the case that the emergence of a bubble crowds out resources for investment, the speculative growth dynamics guarantees that investment still booms along the path. By the same token, if the speculative growth path crashes then no longer the conditions exist for a rational bubble to survive (for the same reason that a bubble cannot exist in the dynamically efficient region 
of the standard model) and it must crash as well. Finally, a bubble that emerges early on in a speculative path is costly because it crowds out potentially welfare improving capital accumulation and because it overexposes the economy to a crash.

We show that a growth-funding feedback arises naturally when an expansion comes with technological progress, especially, in the capital producing sector; when fiscal rules generate sustained fiscal surpluses; when the rest of the world has lower expansion potential; and when financial constraints are relaxed by the expansion itself. Arguably, these ingredients were all simultaneously present in the U.S. during the 1990s.

How does technological progress, especially in the capital producing sector, generate feedback from growth to funding? On one end, technological progress raises future incomes and with it saving available for investment. On the other, relatively fast technological progress in capital producing sectors reduces the saving needed to finance a higher steady-state capital-output ratio. In this context, a fundamental expansion in productivity and stock market speculation are not necessarily competing explanations of an speculative growth episode, as most observers had it during the 1990s. A technological revolution might form an integral part - both as cause and consequence - of a speculative growth equilibrium.

What about fiscal policy? We note that a significant share of increased available funding in the U.S. speculative expansion of the 1990s was attributable to public sector's saving. To the extent that pro-cyclical government revenues increase public saving, they reinforce the feedback from growth to saving. In the short run, fiscal surpluses can arise as a consequence of the boom and can facilitate the initial rise in investment. More importantly, fiscal surpluses can play a central role in making the speculative equilibrium feasible by providing the funding necessary to sustain high investment in the long run. This consideration has a particularly stark implication for fiscal policy during a speculative growth episode. The possibility of using the fiscal surpluses that result from such expansions to cut taxes and raise spending could be illusory, as these surpluses might be necessary to sustain the speculative growth equilibrium that generated them.

A similar role is played by external saving, the other significant source of increase in aggregate saving during the 1990s. In the short run, capital flows alleviate the pressure on short run interest rates brought about by the investment boom. In the long run, if the potential productivity in the high investment equilibrium is higher at home than abroad, then the speculative growth path itself yields a reallocation of global investment toward domestic assets. Moreover, the speculative growth path itself may be made feasible by a 
decline in opportunities abroad.

Finally, if the expansion relaxes financial constraints faced by productive entrepreneurs, then aggregate saving is reallocated toward them. The expansion of the 1990s clearly achieved this goal by facilitating the reallocation of capital toward the mostly small and emerging companies of the new economy sectors. Some of these companies were undoubtedly bubbles and crowded out capital from good firms, but many others were the pillars of the information technology revolution that was so central to the episode.

The speculative growth episodes to which our theory relates are a recurrent phenomenon. Earlier episodes of vigorous economic expansion under speculative asset valuations have been documented by economic historians. In the case of the U.S., this phenomenon also can be observed in the expansions of the turn of the 20th century, the 1920s, and the 1960s (see, e.g., Shiller 2000). Equally important, our theory can be brought to bear on sustained low cost-of-capital equilibria, such as the prolonged expansions exhibited in a number of East Asian economies in the post-war period. In fact, the key feedback from growth to funding in these economies has been documented. Examining the aggregate relationship between income growth and saving in a cross-country panel of 64 countries over the period 1958-1987, Caroll and Weil (1994) find that growth Granger causes saving with a positive sign, but that saving does not Granger cause growth. The pattern of an acceleration in growth followed by strong increases in saving rates is particularly clear in the high-growth, high-saving East Asian economies of Japan, South Korea, Singapore, and Hong Kong. Gavin et al. (1997) elaborate on this evidence and show that the estimated impact of growth on saving is not only statistically significant but also very large in economic terms.

In its economic theme, this paper is part of a long tradition of studies of speculative growth episodes (e.g., Kindleberger 1989). In terms of the recent U.S. experience, this literature is divided between those who see a case of speculative behavior (e.g., Shiller 2000), and those who, based on the significant acceleration in underlying U.S. productivity growth, conclude that the expansion was driven by a technological revolution that affected real fundamentals (e.g., Greenwood and Jovanovic, 1999; Hobijn and Jovanovic, 2000). From this perspective, our contribution is to provide a unified perspective under which these two views need not be mutually exclusive. On the contrary, an expansion of technological opportunities and stock market speculation may come hand on hand.

This perspective finds support in the evidence of Beaudry and Portier (2003), who device a novel semi-structural VAR procedure to conclude that the US business cycle is largely driven by a shock that does not affect productivity in the short run but that is strongly 
related to future productivity growth. They argue that such shock could well represent a coordination device. Similarly, Christiano and Fisher (2003) conclude that the explanatory power of RBC style models is greatly enhanced by the introduction of procyclical investment shocks. In our model, the comovements emphasized by Christiano and Fisher arise from a single shock, and the latter may be mostly of the coordination sort hinted by Beaudry and Portier's findings.

On the methodological side, our paper belongs to the literature on multiple equilibria. This literature is too extensive to review here (see, e.g., Benhabib and Farmer (1999)), but it is interesting to point out some of the similarities and differences with Krugman (1991), who develops a trade model with external economies and adjustment costs. In that model, if adjustment costs are too small, then multiple equilibria arise and expectations dominate. On the other hand, when adjustment costs are large enough, the multiple equilibria region disappears and only history matters. In contrast, in our model multiple equilibria arise only for intermediate adjustment costs. As in Krugman, we need adjustment costs to be small in order to be able to afford a transition to a high capital equilibrium. Unlike Krugman's, we also need adjustment costs to be large enough to generate sufficient capital gains to justify the investment boom along the transition.

We also relate on the methodological and substantive side to the literature on bubbles in general equilibrium. The seminal work by Tirole (1985) set up the foundation for the analysis of bubbles in general equilibrium, but when embedded in the basic unique-equilibrium OLG model it generates implications that are at odds with speculative growth episodes. In particular, it implies that investment and bubbles experience negative comovement and that the latter only can arise in a dynamically inefficient economy. Neither of these elements is observed during these episodes. Partly for this reason, a large literature has developed to modify the basic structure. For example, several papers have demonstrated that, in the presence of externalities that create a wedge between private and social returns on investment, bubbles can arise even if the bubbleless economy is dynamically efficient (e.g., Saint-Paul, 1992; Grossman and Yanagawa, 1993; King and Ferguson, 1993). Ventura (2003) takes this logic a step further and shows that with segmented financial markets bubbles may emerge when only the marginal savers face interest rates below the rate of growth of the economy. Olivier (2000) addresses the negative-comovement problem and shows how bubbles on firm creation can lead to more rather than less investment. Aside from the difference in the specific mechanism we emphasize, in our model conventional rational bubbles exhibit positive comovement with investment and arise even when all investors and savers face high (and private) interest rates. 
The rest of this paper is organized as follows. In section 2, we present a prototypical model of speculative growth. Our analysis is based on the Diamond (1965) overlappinggenerations model, to which we add adjustment costs and a special assumption about the saving function. Adjustment costs allow us to characterize stock market booms and their key role in facilitating the transition from low- to high-investment equilibria. Our special saving function generically captures the growth-funding feedback that is central to the existence of a high-valuation equilibrium. Section 3 discusses the possibility of bubbles and the fragility they introduce to a speculative growth episode. Section 4 presents specific mechanisms that may have facilitated an speculative growth episode in the US during the 1990s. Namely, fiscal surpluses, capital flows, and technological progress in the equipment sector. Section 5 shows how financial constraints a la Kiyotaki and Moore (1997) also have the potential to generate the type of growth-funding mechanisms that we emphasize. Section 6 discusses welfare issues, and Section 7 concludes. Several appendices follow.

\section{Speculative Growth}

In this section we present a prototypical model of speculative growth. Our analysis is based on a linearized version of the Diamond (1965) overlapping-generations model. We capture the growth-funding feedback mechanism through a generic funding function that relaxes Diamond's stability condition. ${ }^{4}$ Our focus in this paper is not so much on what is behind the violation of the stability condition (although we do provide specific mechanisms later on), as is on the other features of the economy that make such modelling change a potentially important source of speculative growth episodes. In Section 4 we discuss specific features that may have played a role in the US episode during the 1990s. In this section, on the other hand, we focus on building the basic structure of the economy. One key ingredient in this structure is the presence of the "right" amount of adjustment costs to capital. With too much adjustment costs, transitions are too costly and equilibrium becomes unique. With too little adjustment costs, there are neither stock market booms nor multiple equilibria, which are central features of the speculative growth episodes we wish to model.

\subsection{The Growth-funding feedback}

Consider a standard Diamond (1965) overlapping-generations structure with no population growth and a unit mass of young and old agents who coexist at any date $t$. Each generation

\footnotetext{
${ }^{4}$ See Diamond (1965), page 1134.
} 
is born with a unit of labor, $\bar{L}=1$, to be used when young, for which it receives a total wage $W_{t}$ determined in a competitive, full-employment labor market. The economy's single consumption good is used as a numéraire.

Consumption goods are produced with capital, $K_{t}$, and labor, $L_{t}$. The production function at any time $t$ is determined by the level of technology, $A_{t}$, which grows at an exogenous rate $\gamma$ :

$$
A_{t+1}=(1+\gamma) A_{t}
$$

Production is given by a constant returns technology, $F\left(K_{t}, A_{t} L\right)$. Letting $k_{t} \equiv K_{t} / A_{t} L_{t}$ denote capital per effective worker, we write the marginal product of capital as:

$$
f_{k}\left(k_{t}\right), \quad f_{k}^{\prime}<0
$$

The labor market is competitive, and the wage $w_{t} \equiv W_{t} / A_{t} \bar{L}$ per unit of effective labor can be written as:

$$
w_{t} \equiv w\left(k_{t}\right) \quad w^{\prime}>0 .
$$

Lifetime utility is a function of consumption during youth and old age. Each member of generation $t$ chooses the level of saving when young, $S_{t}$, that maximizes lifetime utility. The relevant features of preferences are summarized in the level of saving per effective unit of labor, $s_{t} \equiv S_{t} / A_{t} \bar{L}$, which we assume is given by

$$
s_{t}=s\left(w_{t}, r_{t}\right)
$$

where $r_{t}$ denotes the interest rate between periods $t$ and $t+1, s_{w}>0$, and $0<s_{r}<\infty$.

\subsubsection{The long run feedback}

In the Diamond (1965) model, there are no adjustment costs to capital so that $r_{t}=f_{k}\left(k_{t+1}\right)$ and the stock of capital next period is equal to today's saving. Equilibrium then is characterized by a nonlinear difference equation for capital accumulation:

$$
k_{t+1}=\frac{s\left(w\left(k_{t}\right), r\left(k_{t+1}\right)\right)}{1+\gamma}
$$

If the stability condition in Diamond (1965) is relaxed, then multiple steady-states as in panel (a) of Figure 3 can arise. The essential feature of this saving function is that there is a region where saving increases rapidly as capital rises. For now, we do not explain the source of this feature but simply assume it. ${ }^{5}$ A particularly simple formulation of such situation is

\footnotetext{
${ }^{5}$ Note that even if one stays within purely neoclassical features, these need not be exotic. With the technology we use here a log utility would violate the stability conditions.
} 

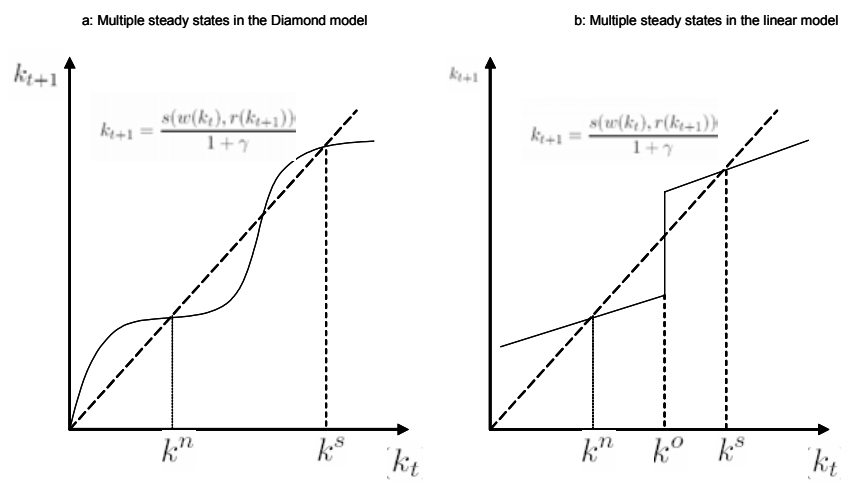

Figure 3: Multiple Steady States

to start with a saving function that is linear in $k$ and $r$, with a step at some level of capital $k^{o}$ :

$$
s\left(w\left(k_{t}\right), r_{t}\right)= \begin{cases}s_{0}+s_{k} k_{t}+s_{r} r_{t}, & k<k^{o} \\ s_{0}+\delta+s_{k} k_{t}+s_{r} r_{t}, & k \geq k^{o}\end{cases}
$$

with $s_{0}, \delta$ and $s_{r} 0$ strictly positive. Now let the marginal product of capital be linear in capital, $\pi_{0}-\pi_{1} k$, with $\pi_{0}$ and $\pi_{1}$ strictly positive and $k \leq \pi_{0} / \pi_{1}$ (henceforth, we will focus on equilibria that satisfy this constraint), so that:

$$
r_{t}=r\left(k_{t+1}\right)=\pi_{0}-\pi_{1} k_{t+1}
$$

Replacing this interest rate expression into the saving function (4), and the result into the capital accumulation expression (3), solves the model. The following assumptions ensure that we capture the scenario that concerns us.

Assumption 0: $\Delta \equiv s_{r} \pi_{1}+\left(1+\gamma-s_{k}\right)>0$ and $\frac{s_{0}+s_{r} \pi_{0}}{\Delta}<k^{0}$.

Assumption 1 (Minimum growth-saving feedback): $\quad \delta>\underline{\delta} \equiv\left(k^{0}-\frac{s_{0}+s_{r} \pi_{0}}{\Delta}\right) \Delta$.

Assumption 1 states that the jump in the saving function at $k^{0}$ must be high enough for a steady state to exist to the right of $k^{0}$.

\section{Proposition 1 (Multiple Steady States)}

If Assumption 0 and 1 are satisfied, the economy has two steady states, $k^{n}$ and $k^{s}$, with:

$$
k^{n}=\frac{s_{0}+s_{r} \pi_{0}}{\Delta}<k^{o}<\frac{s_{0}+\delta+s_{r} \pi_{0}}{\Delta}=k^{s}
$$

where the superscripts " $n$ " and "s" stand for normal and speculative, respectively. 
Proof: See appendix A.

The proposition simply states that if the growth-saving feedback, captured here by the parameter $\delta$, is sufficiently strong, the economy exhibits multiple steady states. This is illustrated in panel (b) of Figure 3.

Importantly, since the marginal product of capital is decreasing in the stock of capital, the speculative steady state exhibits a lower cost of capital than the normal steady state:

$$
r^{s}=r^{n}-\pi_{1} \frac{\delta}{\Delta}<r^{n}
$$

This is the reason at times we refer to the "speculative" equilibrium as the "low cost of capital" equilibrium. Similarly, since the valuation of an asset is simply its price divided by earnings, and in steady state the former is just earnings divided by cost of capital, we have that valuation is just one over the cost of capital. Thus we also refer to the "speculative" equilibrium as the "high valuation equilibrium."

How can the economy have a low cost of capital in the speculative equilibrium when it requires more saving to be sustained? Precisely because higher capital raises saving enough to more than offset the reduction in saving due to the decline in interest rate resulting from lower marginal product of capital (supply of funding shifts more than demand for funding). This is at the core of the growth-funding mechanisms we discuss in this paper.

\subsubsection{Multiple Equilibria}

It is easy to see that while the model above has multiple steady states, it has a unique equilibrium. That is, for any given level of $k_{t}$ the economy converges to a specific steady state. To see this, suppose the economy is at $k^{n}$. Then moving toward $k^{s}$ would require increasing saving, which can only happen if the interest rate rises (since $k_{t}$ is given). But this cannot be an equilibrium since a decreasing marginal product of capital implies that an increase in the interest rate reduces investment. Conversely, suppose that the economy is at $k^{s}$. Then moving toward $k^{n}$ would require lowering saving, which requires the interest rate to fall. But this cannot be an equilibrium either since a fall in the interest rate leads to more rather than less investment. More generally, the same logic applies to any other level of equilibrium capital: If a level of investment constitutes an equilibrium in the capital market for a given level of capital, then no other level of investment (and hence of tomorrow's capital) can be an equilibrium. The reason is simply that for any given $k_{t}$, investment and saving are, respectively, decreasing and increasing with respect to $r_{t}$. 
Let us modify slightly the previous setup and introduce adjustment costs. This not only creates the possibility of a stock market boom, which is one of the features we aim to explain, but also breaks the short run connection between the return on investment and the marginal product of capital (since there are capital gains), which was at the heart of the uniqueness result above.

Let investment to maintain the effective capital stock be frictionless, but all deviations from this level of investment be subject to a convex adjustment cost: ${ }^{6}$

$$
c\left(I_{t}, K_{t}\right)=\frac{1}{2} \theta^{-1} K_{t}\left(\frac{I_{t}}{K_{t}}-\gamma\right)^{2},
$$

where $I$ is investment. As usual, the investment equation in this context takes the simple $q$-theory form:

$$
x\left(q_{t}\right)=\gamma+\theta\left(q_{t}-1\right)
$$

where $x_{t} \equiv I_{t} / K_{t}$ and $q_{t}$ is the price of a unit of installed capital. When adjustment costs are large ( $\theta$ low), investment is relatively unresponsive to deviations of the value of installed capital from that of uninstalled capital. When they are low ( $\theta$ large), investment is very responsive to such deviations. The simple model in the previous section obtains when $\theta$ goes to infinity. The capital accumulation equation can now be written as:

$$
k_{t+1}=\frac{1+x\left(q_{t}\right)}{1+\gamma} k_{t}=\left(1+\frac{\theta}{1+\gamma}\left(q_{t}-1\right)\right) k_{t}
$$

Importantly, it is no longer the case that the interest rate is equal to the marginal product of capital. A unit of installed capital costs $q_{t}$ and saves adjustment costs for $c_{K}\left(I_{t}, K_{t}\right)$ today. This unit of capital yields $q_{t+1}$ and $f_{k}\left(k_{t+1}\right)$ tomorrow. Thus, the return from investing in capital is:

$$
\left(1+r_{t}\right)=\frac{q_{t+1}+f_{k}\left(k_{t+1}\right)}{q_{t}+c_{K}\left(I_{t}, K_{t}\right)}
$$

After replacing $f_{k}$ in it, this expression can be rearranged as:

$$
q_{t+1}=\left(1+r_{t}\right)\left(q_{t}+c_{K}\left(I_{t}, K_{t}\right)\right)-\left(\pi_{0}-\pi_{1} k_{t+1}\right)
$$

with

$$
\begin{aligned}
c_{K}\left(I_{t}, K_{t}\right) & =\frac{1}{2} \theta^{-1}\left(\frac{I_{t}}{K_{t}}-\gamma\right)^{2}-\theta^{-1}\left(\frac{I_{t}}{K_{t}}-\gamma\right) \frac{I_{t}}{K_{t}} \\
& =\frac{1}{2} \theta^{-1}\left(x_{t}-\gamma\right)^{2}-\theta^{-1}\left(x_{t}-\gamma\right) x_{t} \\
& =-\left(\gamma+\frac{\theta}{2}\left(q_{t}-1\right)\right)\left(q_{t}-1\right) .
\end{aligned}
$$

\footnotetext{
${ }^{6}$ Subtracting effective-maintenance investment from the adjustment cost function facilitates our analysis later on without any substantive cost.
} 
The last step to fully specify the dynamic system, is to solve out the interest rate as a function of $q_{t}$ and $k_{t}$. For this, let us find the capital market equilibrium condition. Following production in period $t$, the old sell their capital to the young at price $q_{t}$. The young allocate their saving to the purchase of the existing stock of capital, to invest in new capital, and to pay for the adjustment costs of installing this new capital:

$$
s\left(k_{t}, r_{t}\right)=\left(q_{t}+x_{t}\left(q_{t}\right)\right) k_{t}+c\left(x\left(q_{t}\right), k_{t}\right) .
$$

Replacing (4), (6) and (7) into (10), and solving out for the interest rate, yields:

$$
r\left(q_{t}, k_{t}\right)=\frac{1}{s_{r}}\left\{\left[q_{t}+\gamma+\theta\left(q_{t}-1\right)+\frac{\theta}{2}\left(q_{t}-1\right)^{2}-s_{k}\right] k_{t}-s_{0}-1\left\{k_{t} \geq k^{o}\right\} \delta\right\},
$$

with $1\left\{k_{t} \geq k^{o}\right\}$ an indicator function that takes value one when $k_{t} \geq k^{o}$ and zero otherwise.

Putting things together, the system governing equilibrium dynamics can be written as a two-dimensional system in $\left(k_{t}, q_{t}\right)$-space:

$$
\begin{gathered}
k_{t+1}=\left(1+\frac{\theta}{1+\gamma}\left(q_{t}-1\right)\right) k_{t} \\
q_{t+1}=\left(1+r\left(q_{t}, k_{t}\right)\right)\left(q_{t}-\left(\gamma+\frac{\theta}{2}\left(q_{t}-1\right)\right)\left(q_{t}-1\right)\right)-\left(\pi_{0}-\pi_{1}\left(1+\frac{\theta}{1+\gamma}\left(q_{t}-1\right)\right) k_{t}\right) .
\end{gathered}
$$

It is straightforward to verify that this dynamic system has the same steady states described in Proposition 1. For this, simply note that in steady state $q=1$, in which case the steady state equations of this system collapse to those of the model without adjustment costs.

But the question that concerns us here is under which circumstances the presence of adjustment costs can break the uniqueness result of the simpler model. In particular, whether it is possible for an economy near its "natural" steady state to initiate a path toward the "speculative" one. That is, whether the economy can embark in a "speculative growth" path.

Let us assume that $\delta$ is small so that we can make a first order approximation around $q=1$ and $k=k^{n}$ for the transition from $k^{n}$ to $k^{s}$, if such transition is possible (see the appendix for a precise statement about this approximation, which also requires that the distance between $k^{o}$ and $k^{n}$ be small). Let $\widehat{q_{t}} \equiv\left(q_{t}-1\right)$ and $\widehat{k_{t}} \equiv\left(k_{t}-k^{n}\right)$, then the linearized dynamic system can be written as:

$$
\widehat{q_{t+1}}=\left[\left(1+r^{n}\right)(1-\gamma)+\left(\frac{\pi_{1} \theta}{1+\gamma}+\frac{\theta+1}{s_{r}}\right) k^{n}\right] \widehat{q_{t}}+\frac{\Delta}{s_{r}} \widehat{k_{t}}-1\left\{\widehat{k_{t}} \geq \widehat{k^{o}}\right\} \frac{\delta}{s_{r}},
$$




$$
\widehat{k_{t+1}}=\frac{\theta k^{n}}{1+\gamma} \widehat{q_{t}}+\widehat{k_{t}}
$$

In the appendix we provide the exact statements that make this linear system the limit of the nonlinear one as $\delta$ and $\left(k^{n}-k^{o}\right)$ go to zero. In the main text, our analysis refers to the dynamic system described by (12) and (13). We shall add a technical condition that ensures that the interest rate and marginal product, $f_{k}$, rather than the adjustment cost saving feature of investment, $c_{K}$, dominates local dynamics for all values of $\theta$ :

\section{Assumption 0' (Technical condition): $\quad \frac{k^{n}}{s_{r}}+\left(1+r^{n}\right)(1-\gamma)-1>0$}

It is useful to define the following function:

$$
\Lambda(\theta)=-1+2 \frac{1}{1-\frac{1}{\sqrt{1+\frac{4 \frac{\Delta}{s_{r}} \frac{\theta k^{n}}{1+\gamma}}{\left[\left(1+r^{n}\right)(1-\gamma)+\frac{\pi_{1} \theta k^{n}}{1+\gamma}+\frac{\theta+1}{s_{r}} k^{n}-1\right]^{2}}}}},
$$

which corresponds to the ratio of the slope of the unstable path stemming from the normal steady state to (minus) the slope of the saddle path stemming from the speculative steady state (see the Appendix). Observe that $\Lambda$ is strictly positive, non-monotonic on $[0,+\infty[$, decreasing on $[0, \widetilde{\theta}]$ and increasing on $\left[\widetilde{\theta},+\infty\left[\right.\right.$, with $\lim _{\theta \rightarrow 0} \Lambda(\theta)=\lim _{\theta \rightarrow+\infty} \Lambda(\theta)=+\infty$, where

$$
\widetilde{\theta}=\frac{\frac{k^{n}}{s_{r}}+\left(1+r^{n}\right)(1-\gamma)-1}{\left(\frac{\pi_{1}}{1+\gamma}+\frac{1}{s_{r}}\right) k^{n}} .
$$

Assumption 1' (Minimum growth saving feedback for a transition): $\delta>\underline{\underline{\delta}} \equiv$ $(\Lambda(\widetilde{\theta})+1) \Delta\left(k^{0}-k^{n}\right)$.

Note that since $\Lambda(\widetilde{\theta})>0$, Assumption 1' implies Assumption 1 .

Assumption 2 (Speculative adjustment costs region): $\quad \underline{\theta}(\delta)<\theta<\bar{\theta}(\delta)$, with $\underline{\theta}(\delta)=\inf \left\{\theta>0, \Lambda(\theta)=-1+\frac{\delta}{\Delta\left(k^{0}-k^{n}\right)}\right\}$ and $\bar{\theta}(\delta)=\sup \left\{\theta>0, \Lambda(\theta)=-1+\frac{\delta}{\Delta\left(k^{0}-k^{n}\right)}\right\}$.

\section{Proposition 2 (Multiple Equilibria and Speculative Growth)}

If Assumptions 0, 0', 1' and 2 hold, there is a speculative growth path that takes the economy from $k^{n}$ to $k^{s}$. Along that path, $\widehat{q_{t}}>0$.

Proof: See appendix A.

Let us discuss here the structure of the proof with the help of the phase diagrams in Figure 4. The central ingredients in each of these panels are the unstable arm of the normal 

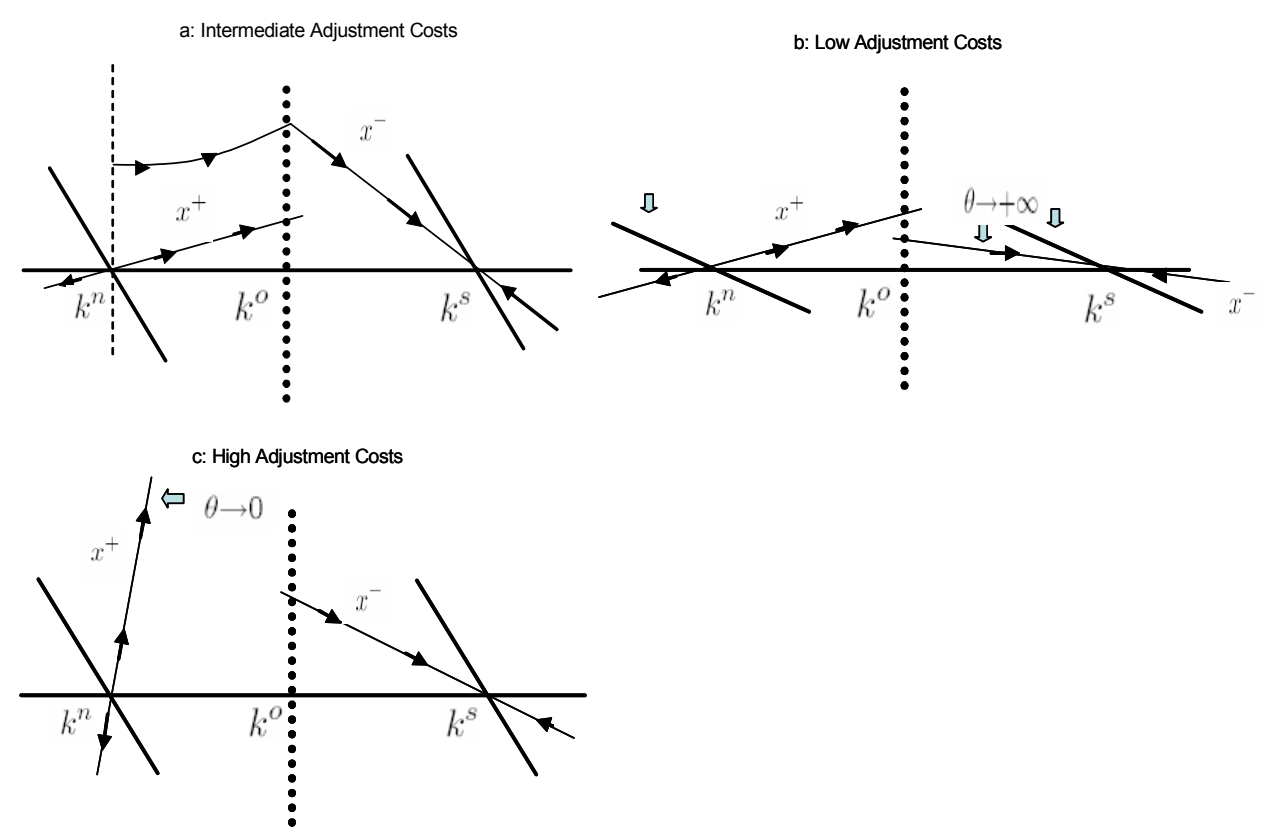

Figure 4: Multiple Equilibria

steady state, the vertical line at $k^{o}$, and the stable arm (saddle path) of the speculative steady state. Naturally, for a speculative growth path to exist, it must be the case that the unstable path of the low capital equilibrium intersects the $k^{o}$ line below the intersection of the latter and the saddle path of the high capital equilibrium. This is precisely the scenario depicted in panel (a). By continuity, in this case there is a path starting at $\left(k^{n}, q^{+}\right)$with $q^{+}>1$, such that it hits $k^{o}$ at the saddle path of the speculative equilibrium.

Before further characterizing the speculative growth path, it is instructive to discuss scenarios where the conditions for such path do not exist. Panels (b) and (c) in Figure 4 provide these examples. The former is one in which adjustment costs are too low (hence $\theta>\bar{\theta}$ ) while the latter represents the other extreme (hence $\theta<\bar{\theta}){ }^{7}$

On one end, when adjustment costs are too low, the slope of the saddle path for the speculative steady state is very flat (small deviations of $q$ from 1 lead to large investment responses). On the other, when adjustment costs are too large, the slope of the unstable path for the normal steady state is very steep (it takes enormous capital gains to justify costly

\footnotetext{
${ }^{7}$ The only reason Proposition 2 is not stated as an if and only if, is that since our linear system is an approximation to the non-linear one, we cannot state whether a speculative growth path is feasible or not when $\theta$ is exactly at the boundaries of the range in Assumption 2. If the inequalities in Assumption 2 are reversed, there is no speculative growth path (see the Appendix). The same consideration applies to most of the Propositions in the main text.
} 
investment beyond maintenance investment). That is, for a speculative growth path to exist, adjustment costs must be large enough to generate sufficient capital gains to decouple the return on investment from the marginal product of capital in the short run, but not so large that it is simply too costly to finance an investment boom.

Returning to panel (a), we can see that along the speculative growth path the value of installed capital is booming and with it are investment and growth. And since marginal product is declining, the price-earnings ratios (valuations) are also rising. These are precisely the features we highlighted in the introduction for the U.S. episode during the 1990s.

\section{$2.2 \quad$ Fragility and crashes}

Our use of the word "speculative" is primarily meant to capture the feedback between the investment boom and capital gains along the path toward the high capital equilibrium. But our framework also captures the meaning of "fragility" in that word.

Assumption 3 (Non-crash adjustment costs region): $\quad \theta \notin\left[\underline{\theta}^{C}(\delta), \bar{\theta}^{C}(\delta)\right]$, where $\underline{\theta}^{C}(\delta)=\inf \left\{\theta>0, \Lambda(\theta)=-1+\frac{\delta}{\Delta\left(k^{s}-k^{0}\right)}\right\}$ and $\bar{\theta}^{C}(\delta)=\sup \left\{\theta>0, \Lambda(\theta)=-1+\frac{\delta}{\Delta\left(k^{s}-k^{0}\right)}\right\}$.

Note that Assumption 3 is automatically satisfied if $\delta<\underline{\underline{\delta}}^{C} \equiv(\Lambda(\widetilde{\theta})+1) \Delta\left(k^{s}-k^{0}\right)$, where the superscript $C$ stands for crash.

\section{Proposition 3 (Consolidation region)}

If Assumptions 0, 0', 1', 2 and 3 hold, there is a speculative growth path that takes the economy from $k^{n}$ to $k^{s}$, but the converse is not true. Moreover, there is a value $k^{c}$ of the capital stock, $k^{o}<k^{c}<k^{s}$, such that there is a unique equilibrium for $k_{t}>k^{c}$ and multiple equilibria for $k^{n} \leq k_{t} \leq k^{c}$.

Proof: See appendix A.

The first part of the proposition is literally Proposition 2. The second part is that at $k^{s}$, there is no path that can take the economy back to $k^{n}$. The structure of the proof is similar to that used in Proposition 2, now to show that when Assumption 3 does not hold, the unstable path from the high capital equilibrium overshoots the saddle path to the low capital equilibrium. The last part of the proposition raises an interesting feature: The economy has a consolidation region. That is, a region around the high capital steady state such that once the economy reaches it, there is no chance of a crash that takes the economy back to the low capital equilibrium. The other side of the coin is that, early on, an economy along a speculative path is fragile and susceptible to crashes. 


\subsection{A Detour: Sunspots}

Of course the concepts of crashes and fragility in a model with multiple but deterministic paths are imprecise at best. But it is conceptually straightforward to introduce a sunspot as an equilibrium-selection device, and formalize these statements.

Suppose, for example, that in the multiple equilibria region the sunspot variable is a Markov chain with two states, $\{u, d\}$, and initial value $e_{0}=u$. When the state is $u$, all agents coordinate their expectations on the speculative growth path. When the state is $d$, expectations coordinate on the path toward the low capital steady state. Define the crash time, $\tau_{d}$ :

$$
\tau_{d}=\inf \left\{t>0, e_{t}=d\right\}
$$

and let the transition probabilities be such that once a crash takes place, the economy converges to the low capital equilibrium with probability one:

$$
\left[\begin{array}{ll}
p_{u u} & p_{u d} \\
p_{d u} & p_{d d}
\end{array}\right]=\left[\begin{array}{cc}
\mu & 1-\mu \\
0 & 1
\end{array}\right] .
$$

Finally, suppose that preferences are such that only the expected return of a project matters to agents (we can use Epstein-Zin preferences for this purpose). With this structure, sunspots do not alter the expression defining the equilibrium interest rate. All that is modified is the expression for expected future price of capital while in the speculative growth path (and not yet in the consolidation region), which is now $\left(\mu q_{t+1}^{u}+(1-\mu) q_{t+1}^{d}\right)$ instead of simply $q_{t+1}$.

For expositional simplicity, we henceforth suppress sunspots from our formal analysis but still use the language of crashes associated to them. ${ }^{8}$ Alternatively, our analysis can be thought of as being conducted in the neighborhood of $\mu=1$.

\section{Bubbles, Assets in Fixed Supply, and Speculative Growth}

Assume momentarily that the speculative steady state is dynamically inefficient, with $r^{s}<$ $\gamma$. It is well known from Tirole (1985) that rational bubbles can emerge in such scenario. Essentially, since a bubble must grow at the interest rate, and the latter is below the rate of growth of the economy, a bubble in this environment never outgrows the economy. Thus, if it is feasible at the outset, it remains so at later dates. Moreover, rational bubbles in this

\footnotetext{
${ }^{8}$ Similarly, we do not model the jump onto a speculative path. We could do so with entirely symmetric sunspot arguments.
} 
context are welfare enhancing since they solve an "excessive" investment problem driven by a high demand for a store of value rather than by productivity considerations. It follows that the emergence of a rational bubble in this context lowers aggregate investment, and that a crash of the bubble boosts aggregate investment.

Now assume that the low capital long run equilibrium, $k^{n}$, is dynamically efficient. In steady state, this means $r^{n}>\gamma$. It is also well known from Tirole (1985) that rational bubbles cannot exist in such environment. If the interest rate exceeds the rate of growth of the economy, a bubble grows faster than the economy until it eventually becomes inconsistent with the aggregate endowment constraint. Backward induction then shows that a rational bubble can simply not emerge in this region.

The fact that most evidence point in the direction of dynamic efficiency in the U.S. (Abel et al (1989)) and that episodes of speculative growth as illustrated in Figure 1 exhibit strong positive comovement between valuations and investment, would seem to be conclusive evidence against the presence of rational bubbles during these episodes. It turns out that neither property needs to hold in our speculative growth environment. Along a speculative growth path bubbles may emerge even in the region where the interest rate exceeds the rate of growth of the economy. Moreover, aggregate investment and the bubble experience positive comovement. The speculative growth path is needed for a bubble to emerge, and if the economy crashes into the recessionary path toward the low capital equilibrium, so will the bubble. Importantly, the likelihood of such crash is enhanced by the emergence of a bubble.

\subsection{Bubbles with $r>\gamma$}

Assumption 4 (Bubble region): $\quad \pi_{0}-\pi_{1} k^{n}>\gamma>\pi_{0}-\pi_{1} k^{0}$

\section{Proposition 4 (Bubbles in high interest region)}

Let Assumptions 0, 0', 1', 2 and 4 hold, and initial capital be equal to $k^{n}$. Then, if the economy initiates a speculative growth path, there will a range of feasible rational bubbles (normalized by $A(t)), b_{t}$, such that $b_{0}>0$ and

$$
b_{t+1}=\frac{1+r_{t}}{1+\gamma} b_{t}
$$

Proof: See appendix B.

This result is intuitive. While at the outset of the speculative growth path the economy is in a region where the interest rate exceeds the rate of growth of the economy, it is headed toward a dynamically inefficient region where bubbles can be sustained. But then, by 
backward induction, bubbles can start before the economy reaches that region. All that is required is that the initial bubble be sufficiently small so that despite its fast early growth, it reaches the dynamically inefficient region with a size consistent with the bounds imposed by the size of the economy, and that it allows capital to grow and reach that region.

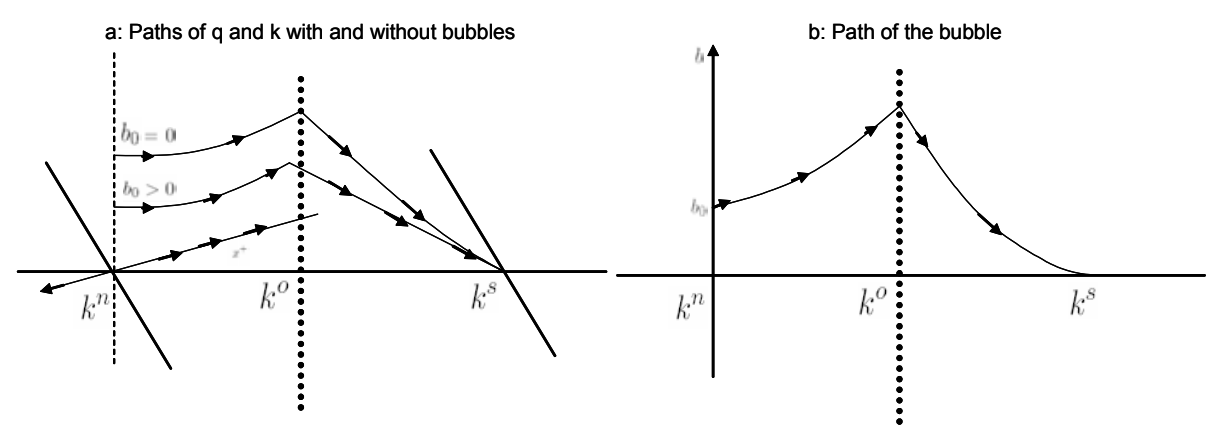

Figure 5: Bubbles

Figure 5 shows one such example. Panel (a) illustrates the paths of $q$ and $k$ for two economies along a speculative path, one with and the other without a rational bubble. Panel (b) illustrates the path of the bubble.

\subsection{Bubbles and crashes}

\section{Proposition 5 (Bubbles and fragility)}

Let Assumptions 0, 0', 1', 2, 3 and 4 hold, and initial capital be equal to $k^{n}$. Then, the length of time an economy along a speculative growth path remains outside the consolidation region (and hence is susceptible to a crash), is increasing with respect to the size of the bubble, $b_{t}$.

Proof: See appendix B.

The reason for this result is intuitive as well. As in the standard model, a bubble competes for savings with physical investment. This means that in the presence of a bubble, the economy transits more slowly from $k^{n}$ to $k^{s}$ all along the path, which also means that it takes longer for the economy to reach the consolidation region, $k \geq k^{c}$. Note that while a bubble still crowds out investment, it now exhibits positive rather than negative comovement with aggregate investment. In particular, the bubble can only emerge when the investment is booming along a speculative path. And if the latter crashes, so will the bubble. 

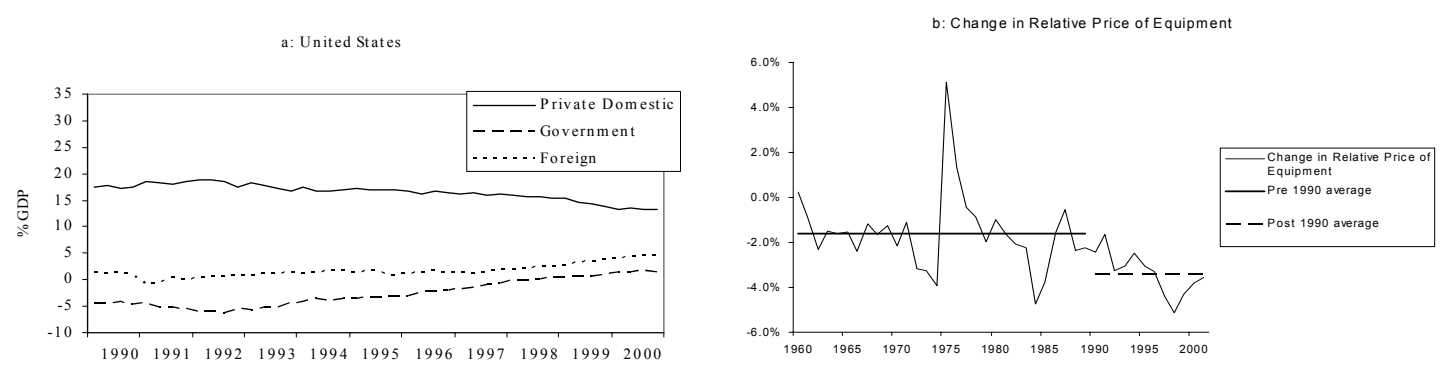

Figure 6: Mechanisms in the US Epidode

\section{Mechanisms in the US Episode}

Sections 2 and 3 have described an environment that is conducive to speculative growth episodes that resemble those portrayed in Figure 1. At the core of this result is optimism about future effective funding of large capital accumulation. In this section we discuss a few prominent features of the US economy during the 1990s that supported this optimism: Fiscal surpluses, capital flows, and technological progress in the equipment sector.

\subsection{Fiscal surpluses}

The fiscal surpluses generated during the U.S. speculative growth experience were the combined result of fiscal consolidation measures and the automatic effect of procyclical tax revenues in a booming environment. The reduction in public debt had a moderating effect on interest rates in the short run and substituted for increased private saving to fund the investment boom. It is in this sense that a tight policy of paying down the national debt supported the boom in the short term. Turning to the more novel issue of longer-term sustainability, we argue that a continuing policy rule of generating fiscal surpluses provides critical support to the speculative equilibrium.

To develop our argument, we add a government to the model. We assume the government taxes wage income at a rate $\tau_{t}$ and spends $g_{t} A_{t} L$ on goods that do not enter agents' utility function. Thus the government's budget constraint is

$$
(1+\gamma) d_{t+1}=\left(1+r_{t}\right)\left[d_{t}-\left(\tau_{t} w_{t}-g_{t}\right)\right]
$$

where $d_{t} \equiv D_{t} / A_{t} L$ denotes public debt per unit of effective labor.

Adding the public sector alters two equations in the model. The saving of the young $s_{t}$, 
is now a function of after-tax wages:

$$
s_{t}=s\left(\left(1-\tau_{t}\right) w\left(k_{t}\right), r_{t}\right)
$$

while the capital-market equilibrium condition is now given by

$$
\left(\tau_{t} w_{t}-g_{t}\right)+s_{t}=d_{t}+\left(q_{t}+x\left(q_{t}\right)\right) k_{t}+c\left(x\left(q_{t}\right), k_{t}\right)
$$

The saving of the government and of the young must fund the purchase of the existing public debt and capital stock from the old, and new investment. Combined, equations (15)(16) implicitly define a new interest rate function $r_{t}=r\left(k_{t}, q_{t}, d_{t}, \tau_{t}, g_{t}\right)$. The economy's dynamics are described by system (8)-(9) with the new interest rate function together with the government budget constraint, (14), and a fiscal policy rule.

Let us consider a benchmark fixed-parameters policy rule under which detrended government spending and the tax rate are fixed at $\bar{g}>0$ and $\bar{\tau}>0$. To facilitate comparisons, we assume that this and other policy rules result in a balanced budget in the low-valuation steady state — which requires $\bar{g}=\bar{\tau} w^{n}$ — and, therefore, result in the same low valuation steady state. The important point to notice is that this fixed-parameters policy creates primary surpluses during expansions beyond $k^{n}$ and primary deficits during contractions. To see this, note that the fiscal rule implies that the primary government surplus, $\left(\bar{\tau} w_{t}-\bar{g}\right)$, increases with $w_{t}$ in an expansion. Thus the response of the combined "gross" saving of government and the young to an increase in wages is given by $\left(\bar{\tau}+s_{w}(1-\bar{\tau})\right) d w_{t}$.

The increase in saving generated by the fixed-parameters rule not only facilitates the funding of investment in the short run but, more importantly, plays a central role in facilitating the emergence of a speculative growth scenario. This feasibility point is made most clearly by focusing on the speculative steady state, $\left(k^{s}, 1\right)$, rather than on the entire path. One can show that if, instead of being fixed, government spending is raised with the endogenous increase in the wage, then aggregate saving falls and so does the level of $k^{s}$. In fact this fiscal expansion experiment is similar to reducing $\delta$ in Section 2. For a high enough indexation of fiscal spending to wages, the speculative equilibrium is no longer feasible. In other words, fiscal surpluses are not only a symptom of the speculative growth episode, but also can be a central element of the factors that support it.

The notion that the fiscal surpluses generated by the speculative equilibrium can be partly spent or rebated to the taxpayer may be an illusion. The surpluses could be a pillar of the speculative equilibrium, and might swiftly disappear if this equilibrium unravels giving rise to what one might describe as a surplus illusion. 
The following proposition summarizes our results: ${ }^{9}$

\section{Proposition 6 (Surplus Illusion)}

Let Assumptions 0, 0', 1', 2 and 4 hold. Let $g_{t}=\bar{g}+\alpha \bar{\tau}\left(w_{t}-w^{n}\right)$. If the economy has two saddle-path steady state equilibria for $\alpha=0$, there exists an $\alpha^{m}>0$ such that for any $\alpha \geq$ $\alpha^{m}$, the speculative equilibrium disappears. An upper bound for $\alpha^{m}$ is $\max \left\{\frac{\Delta}{\pi_{1} k^{n}} \frac{\delta}{k^{0}-k^{n}}(1-\right.$ $\left.\left.\frac{k^{0}-k^{n}}{\frac{\delta}{\Delta}}\right), \bar{\tau}\right\}$.

Proof: See appendix C.

Importantly, the parameter $\alpha^{m}$ is less than one for a wide configuration of parameters.

\subsection{Capital flows}

The other major source of funding for the investment boom in the U.S. was the current account. As a short-term funding mechanism, international capital flows can moderate the rise in interest rates needed to fund the investment boom. Over time, the whole world may be dragged into a speculative path. ${ }^{10}$

We capture the key role played role by capital flows in facilitating a speculative growth episode with a stark contrast. One in which no such episode will be feasible without the presence of external saving. For this purpose, let us assume that the closed economy saving function does not depend on the interest rate, $s_{r}=0$. In this case, if the home country were in autarky, the transition from the normal steady state to the speculative one would be impossible. This is because saving, and therefore investment, are fully determined by $k^{n}$, with no role for interest rates in facilitating an investment boom.

Let us now introduce a simple foreign country. In it, the young receive an aggregate endowment $\widetilde{e_{t}}=\widetilde{e}(1+\gamma)^{t}$ in each period, which they save in full. The economy also has a technology that uses only capital to produce consumption goods:

$$
\widetilde{F}\left(Z_{t}\right)=A_{t} \tilde{f}\left(\frac{Z_{t}}{A_{t}}\right)=A_{t} \widetilde{f}\left(z_{t}\right) ; \quad \widetilde{f}^{\prime}>0, \widetilde{f}^{\prime \prime}<0
$$

where (foreign) capital $Z_{t}$ is accumulated without adjustment costs. Because this production function exhibits decreasing returns to scale, there are quasi-rents which accrue to an

\footnotetext{
${ }^{9}$ In the proposition, we also add the condition that the speculative equilibrium be dynamically inefficient in order to avoid explosive assets or debt. This is necessary only because we are analyzing simple linear fiscal rules.

${ }^{10}$ Ventura (2001) emphasizes an alternative portfolio channel connecting the current account and a domestic bubble. In his model, the main effect of the bubble is to raise domestic wealth. As domestic agents attempt to rebalance their portfolios by investing in non-bubbly domestic equity, external borrowing rises to finance the investment that is required to build domestic equity.
} 
unmodeled factor of production, which does not save (this is not important). Let the marginal product of capital from this technology be linear in capital, $\widetilde{\pi_{0}}-\widetilde{\pi_{1}} z$, with $\widetilde{\pi_{0}}$ and $\widetilde{\pi_{1}}$ strictly positive and $z \leq \widetilde{\pi_{0}} / \widetilde{\pi_{1}}$ (henceforth, we will focus on equilibria that satisfy this constraint). Since capital markets are integrated, it must be that:

$$
r_{t}=r\left(z_{t+1}\right)=\widetilde{\pi_{0}}-\widetilde{\pi_{1}} z_{t+1}
$$

Equilibrium in global capital market is now:

$$
s\left(k_{t}\right)+\widetilde{e}=\left(q_{t}+x_{t}\left(q_{t}\right)\right) k_{t}+c\left(x\left(q_{t}\right), k_{t}\right)+(1+\gamma) z_{t+1},
$$

while the arbitrage and capital accumulation equations for $k$ are still given by (9) and (8).

We can now solve $z_{t+1}$ out from (17):

$$
z_{t+1}=\frac{\widetilde{\pi_{0}}-r_{t}}{\widetilde{\pi_{1}}}
$$

and replace it in (18) to obtain an effective saving function (by which here we mean saving available for investment in $k$ ):

$$
s^{e}\left(k_{t}, r_{t}\right) \equiv s\left(k_{t}\right)+\widetilde{e}-\frac{\widetilde{\pi_{0}}(1+\gamma)}{\widetilde{\pi_{1}}}+\frac{1+\gamma}{\widetilde{\pi_{1}}} r_{t}
$$

It is now straightforward to see that with $s_{0}^{e}=s_{0}+\widetilde{e}-\frac{\widetilde{\pi_{0}}(1+\gamma)}{\pi_{1}}, s_{k}^{e}=s_{k}$ and $s_{r}^{e}=\frac{1+\gamma}{\pi_{1}}$, we can fully reproduce the analysis of Section 2 with $s^{e}\left(k_{t}, r_{t}\right)$ replacing $s\left(k_{t}, r_{t}\right)$ in Section's 2 formulae. In particular, the domestic economy now can initiate a speculative path which would have been infeasible in autarky.

Early on in this path, the interest rate rises, and foreign saving flows into the home economy while foreign output declines. Over time, as the growth-saving feedback gains in strength, the domestic economy pulls the foreign economy by reversing the capital flows.

Interestingly, as it may have played an important role during the 1990s, the mechanism above also implies that if there is an exogenous decline in foreign opportunities, this may facilitate a transition into a speculative episode in the home economy. Furthermore, if the transition comes together with the decline in opportunities abroad, interest rates need not rise in the short run either.

Let us suppose that with $s^{e}\left(k_{t}, r_{t}\right)$ replacing $s\left(k_{t}, r_{t}\right)$, Assumptions 0, 0' and 1 hold but Assumption 2 does not hold, so that no transition from the normal steady state to the speculative steady state is possible. Consider a situation where the economy is initially in 
the low steady state. Let us now imagine that $\widetilde{e}$ and $\widetilde{\pi_{0}}$ unexpectedly shift to $\widetilde{e} \geq \widetilde{e}$ and $\widetilde{\pi_{0}} \leq \widetilde{\pi_{0}}$, so that $s_{0}^{e}$ shifts to $s_{0}^{e \prime}=s_{0}^{e}+\left(\widetilde{e^{\prime}}-\widetilde{e}\right)-\left(\widetilde{\pi_{0}}-\widetilde{\pi_{0}}\right) \frac{1+\gamma}{\pi_{1}} \geq s_{0}^{e}$.

Assumption 5: $\quad \Delta\left(k^{0}-k^{n}\right)>s_{0}^{e \prime}-s_{0}^{e}>\Delta\left(k^{0}-k^{n}\right)-\frac{\delta}{(\Lambda(\theta)+1)}>0$.

This assumption implies that there are two steady states under the new parameters. Denote them by $k_{n}^{\prime}=k_{n}+\frac{s_{0}^{e \prime}-s_{0}^{e}}{\Delta}$ and $k_{s}^{\prime}=k_{s}+\frac{s_{0}^{e \prime}-s_{0}^{e}}{\Delta}$.

\section{Proposition 7 (Change in conditions in the rest of the world)}

If Assumption 5 holds, there is no transition from $k^{n}$ to $k^{s}$ under the parameters $\tilde{e}$ and

$\tilde{\pi_{0}}$. By contrast, there are multiple equilibria under the parameters $\tilde{e^{\prime}}$ and $\tilde{\pi_{0}^{\prime}}$ : starting with capital stock $k^{n}$, there is a saddle path that takes the economy from $k^{n}$ to $k^{n^{\prime}}$ and a speculative growth path that takes the economy from $k^{n}$ to $k^{s^{\prime}}$. Along these paths, $\widehat{q_{t}}>0$.

The result is intuitive. If saving in the foreign country increase or if the rate of return in the foreign country decreases, causing a reallocation of saving to the domestic economy, a speculative growth scenario can emerge where it would have been impossible before the shift.

\subsection{Technological progress in the equipment sector}

The productivity growth that came with technological progress was exceptional. After two disappointing decades beginning with the oil price shocks of the 1970s, the economy recovered more than half of its lost productivity growth. Most prominently, productivity growth in industrial and electronic machinery accelerated from an annual rate of $2 \%$ for 1973-1990 to more than 6\% for 1995-2000. This acceleration reduced the price of machinery and electronic devices, which in turn contributed to the investment boom. This mechanism fits within the speculative growth perspective we have highlighted up to now, once one broadens the definition of funding to that of effective funding. That is, for any given level of saving, a decline in the price of new capital raises the power of that saving to build the economy's stock of capital.

While some of the technological progress in equipment producing sectors may have been exogenous to the capital deepening process itself, we continue here with our endogenous perspective (which in any event would act as a multiplier to the exogenous shocks). We capture this endogeneity through a positive spillover from the capital accumulation process to the production of equipment goods. ${ }^{11}$ This simple channel allows us to preserve much of

\footnotetext{
${ }^{11}$ See Murphy et al. (1989) for a model of this sort based on increasing returns in the equipment sector, and Jaimovich (2003) for a countecyclical markups version.
} 
our previous formulae. Moreover, here we set $\delta=0$ as the technological spillover ends up playing a similar role in the current model.

We assume that the technology in the equipment goods sectors can transform one unit of consumption goods into $\lambda(k)$ units of equipment goods (with $\lambda^{\prime}>0$ ). Perfect competition in this sector ensures that the price of equipment goods is:

$$
p\left(k_{t}\right)=\frac{1}{\lambda\left(k_{t}\right)}
$$

Since $q_{t}$ corresponds to Tobin's q - that is as the value of a unit of installed capital over the price on a new (uninstalled) unit of capital - we preserve the formulae of Section 2, with two exceptions: the capital market equilibrium condition and the arbitrage equation.

The former is now:

$$
s\left(k_{t}, r_{t}\right)=p\left(k_{t}\right)\left(q_{t}+x_{t}\left(q_{t}\right)\right) k_{t}+p\left(k_{t}\right) c\left(x\left(q_{t}\right), k_{t}\right)
$$

But is apparent that by dividing both side of this condition by $p\left(k_{t}\right)$ and defining the effective funding function as:

$$
s^{p}\left(k_{t}, r_{t}\right) \equiv \frac{s\left(k_{t}, r_{t}\right)}{p\left(k_{t}\right)}
$$

we can rewrite (19) as:

$$
s^{p}\left(k_{t}, r_{t}\right)=\left(q_{t}+x_{t}\left(q_{t}\right)\right) k_{t}+c\left(x\left(q_{t}\right), k_{t}\right),
$$

which is entirely analogous to the equilibrium capital market condition in Section 2.

Moreover, suppose that we model the aggregate increasing returns aspect of the equipment sector as a simple step function:

$$
p\left(k_{t}\right)= \begin{cases}1, & k_{t}<k^{o} \\ p<1, & k \geq k^{o}\end{cases}
$$

then $(1-p)>0$ is isomorphic to $\delta$ in terms of the effective funding or saving function.

The only difference with the model in Section 2 is that $(1-p)$ affects not only effective funding, but also the arbitrage equation, since now:

$$
q_{t+1}=\left(1+r_{t}\right)\left(q_{t}+c_{K}\left(I_{t}, K_{t}\right)\right) \frac{p\left(k_{t}\right)}{p\left(k_{t+1}\right)}-\frac{\left(\pi_{0}-\pi_{1} k_{t+1}\right)}{p\left(k_{t+1}\right)} .
$$

However, nothing of our fundamental message is changed by this modification. In particular, the pre-conditions and features of the speculative path remain valid. We prove these claims in Appendix C.3. 


\section{$5 \quad$ Financial Constraints and Growth-funding feedbacks}

Another key ingredient in the US episode is the reallocation of funding toward small growth firms in new technology sectors. We develop this model here with two purposes. First, to show that a growth-funding mechanism need not operate through aggregate saving; the reallocation of funds can play a similar role. Second, to show a more explicit model of $\delta$; here the growth-funding feedback stems from the relaxation of financial constraints brought about by the expansion.

Let us simplify interest rate determination by assuming that there is a constant returns to capital, $h$, sector with (low) productivity $r$, which is always active so that the "riskless" interest rate is pinned down at $r$.

More substantively, assume that only a fraction $\mu<1$ of the new born can invest and work in the conventional sector described in Section 2, while the rest of the young (lenders) work in a sector that has no capital. Thus, aggregate output is:

$$
Y_{t}=A_{t}\left(\mu L f\left(k_{t}\right)+(1-\mu) L+r h_{t}\right)
$$

Young lenders have undiscounted log-utility preferences, so they save half of their wages, which in aggregate amounts to $(1-\mu) / 2$. We assume that $(1-\mu)$ is large enough so their saving is never binding in equilibrium. Entrepreneurs, on the other hand, satisfy a minimum (detrended) consumption $\bar{c}$, after which they save and invest as much as they can:

$$
\mu\left(w\left(k_{t}\right)-\bar{c}\right)
$$

In equilibrium, entrepreneurs borrow from lenders, $d_{t}$ :

$$
d_{t}=\left(x_{t}+q_{t}+\frac{1}{2} \theta^{-1}\left(x_{t}-\gamma\right)^{2}\right) k_{t}-\mu\left(w\left(k_{t}\right)-\bar{c}\right) .
$$

Against this loans, entrepreneurs post as collateral the capital they acquire:

$$
q_{t+1} k_{t} /(1+r)
$$

Neither new investment nor output can be pledged (this is our financial constraint). Collateralized loans are made at the "riskless" interest rate $r$. Uncollateralized loans consume (per unit) $\delta / s_{r}$ resources in monitoring and therefore are made at interest rate $r+\delta / s_{r}$.

For a given interest rate, neither the accumulation equation nor the arbitrage condition described in Section 2 change in this model. The main change is in the criterion separating the two regions of the phase diagram. Rather than $k^{o}$, now there is a condition that splits 
the region according to whether the marginal loan is collateralized (and hence at rate $r$ ) or not (and hence at rate $r+\delta$ ). For this purpose, let us define

$$
n_{t} \equiv d_{t}-\frac{q_{t+1} k_{t}}{1+r}
$$

By replacing (23), the arbitrage condition, and the accumulation equation into this expression, we obtain:

$n_{t}=\left(\gamma+\theta\left(q_{t}-1\right)+\frac{\theta}{2}\left(q_{t}-1\right)^{2}\right) k_{t}-\mu\left(w\left(k_{t}\right)-\bar{c}\right)+\left(\frac{1+r_{t}}{1+r} \frac{\theta}{2}\left(q_{t}-1\right)^{2}+\frac{1+r_{t}}{1+r} \gamma\left(q_{t}-1\right)+\frac{f^{\prime}\left(\frac{1+\gamma+\theta\left(q_{t}-1\right)}{1+\gamma} k_{t}\right)}{1+r}\right) k_{t}$.

When $n\left(q_{t}, k_{t}\right) \leq 0$ the interest rate is $r$, while when $n_{t}>0$ the interest rate is $r+\delta / s_{r}$. We are now in the setting of Section 2 with only a slightly more complicated function separating the two regions of the phase diagram. Note that if $n_{t}=0$, then $r_{t}=r$. Using this and simplifying, the separating region is defined by the following equation

$$
0=\left[\gamma+(\theta+\gamma)\left(q_{t}-1\right)+\theta\left(q_{t}-1\right)^{2}\right] k_{t}-\mu\left(w\left(k_{t}\right)-\bar{c}\right)+\frac{f^{\prime}\left(\frac{1+\gamma+\theta\left(q_{t}-1\right)}{1+\gamma} k_{t}\right)}{1+r} k_{t} .
$$

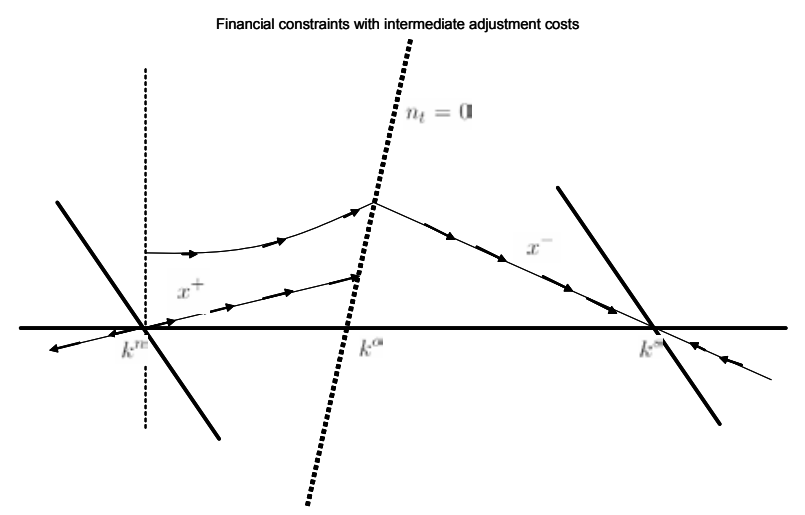

Figure 7: Financial Constraints

Figure 7 illustrates the analogue of panel (a) in Figure 4. As before, there are two steady states and the possibility of a speculative growth path. The key funding-growth feedback now arises from the fact that the financial constraint is no longer binding when $k$ is sufficiently large, which significantly drops the interest rate on loans. Appendix D proves the main claims in this section; in particular, it reproduces the main result of the paper in the context of this model. 


\section{Welfare}

Do speculative growth episodes represent a Pareto improvement across generations involved in it? The answer to this question is not generic, as it depends on the specific channel behind the growth funding feedback. For example, in the financial constraints model of the previous section the answer is yes. But it needs not be the case if $\delta$ is a property of the aggregate saving function as some savers after $t^{o}$ (the time at which $k_{t}$ first reaches $k^{o}$ ) are hurt by the sharp decline in interest rates.

\subsection{Generic results}

But what is generic in our models is the welfare improvement of all generations born before $t^{o}$. It is also generic that if the economy is dynamically efficient then all generations with capital close enough to the high capital equilibrium are also better off. We summarize these results in two propositions, and explain them through their short proofs.

\section{Proposition 8 (Welfare for early generations)}

Let the conditions for the multiple equilibria outcome in the cannonical model in Section 2 hold. Then all generations $t<t^{o}$ are better off along a speculative path than in the low capital steady state.

\section{Proof:}

The basket consumed by individuals of generation $t$ in the low capital steady state is affordable along the speculative growth path if:

$$
w_{t} \geq w^{n}-s^{n}+s^{n} \frac{1+r^{n}}{1+r_{t}}
$$

where $s^{n}$ denotes detrended savings by an individual in the low capital equilibrium.

For generations $t \leq t_{0}$, which are the ones that concern us in this proposition, we have $r_{t}>r^{n}$ since $q_{t}>1, k_{t}>k^{n}, r_{k}>0$ and $r_{q}>0$, and $w_{t}>w_{n}$ since $k_{t}>k^{n}$ and $w_{k}>0$. Therefore, (24) is always verified for these generations.

Q.E.D.

\section{Proposition 9 (Welfare for late generations)}

Let the conditions for the multiple equilibria outcome in the cannonical model in Section 2 hold. Then if the speculative steady state is dynamically efficient $\left(r^{s} \geq \gamma\right)$, all generations near the speculative steady state are better off than in the normal steady state. Conversely, if $r^{s} \leq(1+\gamma) \frac{k^{n}}{k^{s}}-1$, then all generations near the speculative steady state are worse off than in the normal steady state. 
Observe that $(1+\gamma) \frac{k^{n}}{k^{s}}-1<\gamma$.

\section{Proof:}

For generations $t \geq t^{o}$, whether the key inequality in the previous proposition is satisfied is ambiguous. We still have $w_{t}>w^{n}$ but now the sign of $r_{t}-r^{n}$ is ambiguous.

The capital market equilibrium condition in the low equilibrium is

$$
s^{n}=\left(q^{n}+x^{n}+\frac{1}{2} \theta^{-1}\left(x^{n}-\gamma\right)^{2}\right) k^{n}=(1+\gamma) k^{n} .
$$

In the speculative steady state, we can rewrite (24) as

$$
f\left(k^{s}\right)-k^{s} f^{\prime}\left(k^{s}\right)-f\left(k^{n}\right)-k^{n} f^{\prime}\left(k^{n}\right) \geq \frac{1+\gamma}{1+f^{\prime}\left(k^{s}\right)} k^{n}\left(f^{\prime}\left(k^{n}\right)-f^{\prime}\left(k^{s}\right)\right) .
$$

Since $f$ is strictly concave, we have that

$$
\left(k^{s}-k^{n}\right) f^{\prime}\left(k^{s}\right)<f\left(k^{s}\right)-f\left(k^{n}\right)<\left(k^{s}-k^{n}\right) f^{\prime}\left(k^{n}\right) .
$$

Therefore,

$$
k^{n}\left(f^{\prime}\left(k^{n}\right)-f^{\prime}\left(k^{s}\right)\right)<f\left(k^{s}\right)-k^{s} f^{\prime}\left(k^{s}\right)-f\left(k^{n}\right)-k^{n} f^{\prime}\left(k^{n}\right)<k^{s}\left(f^{\prime}\left(k^{n}\right)-f^{\prime}\left(k^{s}\right)\right) .
$$

Assume first that $r^{s}=f^{\prime}\left(k^{s}\right) \geq \gamma$. Then

$$
\frac{1+\gamma}{1+f^{\prime}\left(k^{s}\right)} k^{n}\left(f^{\prime}\left(k^{n}\right)-f^{\prime}\left(k^{s}\right)\right) \leq k^{n}\left(f^{\prime}\left(k^{n}\right)-f^{\prime}\left(k^{s}\right)\right)
$$

so that (25) is verified with a strict inequality. Since $\lim _{t \rightarrow+\infty} w_{t}=w^{s}$ and $\lim _{t \rightarrow+\infty} r_{t}=r^{s}$, this proves the first claim in the proposition.

Assume now that $r^{s}=f^{\prime}\left(k^{s}\right) \leq(1+\gamma) \frac{k^{n}}{k^{s}}-1$. Then

$$
\frac{1+\gamma}{1+f^{\prime}\left(k^{s}\right)} k^{n}\left(f^{\prime}\left(k^{n}\right)-f^{\prime}\left(k^{s}\right)\right) \geq k^{s}\left(f^{\prime}\left(k^{n}\right)-f^{\prime}\left(k^{s}\right)\right)
$$

so that $(25)$ is violated. This proves the second claim in the proposition.

Q.E.D.

\subsection{A comment on Bubbles and Welfare}

In the classic model of rational equilibrium bubbles, the latter are good because they reduce the overaccumulation problem of a dynamically efficient economy. This welfare enhancing features of bubbles runs counter most observers intuition during speculative growth episodes. 
Our model shares that positive side of bubbles for generations very late in the speculative growth episode but they have a negative side as well: they overexpose the economy to crashes by delaying the arrival of the consolidation phase. ${ }^{12}$

In other words, if bubbles emerge late in the process once the economy has already arrived to the consolidation region, they are more likely to be beneficial. But bubbles that arise early in the speculative growth path risk derailing this potentially prosperous process.

\section{$7 \quad$ Final Remarks}

This paper builds a theoretical framework for thinking about episodes of speculative growth. We characterize this phenomenon as a low effective cost-of-capital equilibrium based on optimism about the future availability of funds for investment. Our framework highlights the key short-term and long-term funding mechanisms necessary to sustain a speculative growth equilibrium.

Ours is not a framework of "irrational exuberance," although it offers a natural interpretation of such episodes. These occur when a speculative growth path is not backed by a long-run funding mechanism strong enough to eventually validate the capital gains dynamics that are needed in the short run to reallocate resources toward the sectors that drive the boom. A prototypical example is when investment and speculation focus on the "wrong" sector, as it may have been the case in Japan during the 1980s with its large real estate boom.

The U.S. experience during the 1990s probably had elements of both: A rational speculative growth component built on the information technology sector, sound fiscal policy, and foreigners' confidence, as well as some elements of irrationality especially during the late 1990s. From this perspective, it is not at all clear whether much of the U.S. asset markets boom during the 1990s, even if bubbly, was condemned to be reversed. On this regard, an interesting question that we leave for future research is whether a central bank should attempt to raise interest rates upon the emergence of bubbles. It may well be the case that doing so not only crashes the bubbles but also the underling, and mostly welfare enhancing, speculative growth episode.

\footnotetext{
${ }^{12}$ Note that this postponement has a distributional effect as well as it extends the number of generations before $t^{o}$, which are unambiguously better off with the speculative growth episode.
} 


\section{A Proof of Propositions in Section 2}

\section{Proof of Proposition 1:}

The conditions for a steady state are $q=1, r=\pi_{0}-\pi_{1} k, s_{0}+s_{k} k+s_{r} r+1\left\{k \geq k^{o}\right\} \delta=$ $(1+\gamma) k . k^{n}<k^{0}$ is a steady state if and only if $k^{n}=\frac{s_{0}+s_{r} \pi_{0}}{\Delta}<k^{0}$. This inequality holds by Assumption 0. Similarly $k^{s} \geq k^{0}$ is a steady state if and only if $k^{s}=\frac{s_{0}+s_{r} \pi_{0}+\frac{\delta}{s_{r}}}{\Delta}>k^{0}$. This last inequality holds by Assumption 1.

Q.E.D.

\section{Proof of Proposition 2:}

Let $\widehat{q_{t}} \equiv\left(q_{t}-1\right)$ and $\widehat{k_{t}} \equiv\left(k_{t}-k^{n}\right)$, then the linearized dynamic system around the normal steady state can be written as:

$$
\begin{gathered}
\widehat{q_{t+1}}=\left[\left(1+r^{n}\right)(1-\gamma)+\left(\frac{\pi_{1} \theta}{1+\gamma}+\frac{\theta+1}{s_{r}}\right) k^{n}\right] \widehat{q_{t}}+\left[\pi_{1}+\frac{1+\gamma-s_{k}}{s_{r}}\right] \widehat{k_{t}} \\
\widehat{k_{t+1}}=\frac{\theta k^{n}}{1+\gamma} \widehat{q_{t}}+\widehat{k_{t}} .
\end{gathered}
$$

This system is characterized by the following $2 \times 2$ matrix:

$$
\Omega=\left[\begin{array}{cc}
\left(1+r^{n}\right)(1-\gamma)+\frac{\pi_{1} \theta k^{n}}{1+\gamma}+\frac{\theta+1}{s_{r}} k^{n} & \pi_{1}+\frac{1+\gamma-s_{k}}{s_{r}} \\
\frac{\theta k^{n}}{1+\gamma} & 1
\end{array}\right] .
$$

The two eigenvalues $\lambda^{+}$and $\lambda^{-}$of $\Omega$ are real since the $\operatorname{discriminant} D$ of $\operatorname{det}(\Omega-x I)$ is positive:

$$
D=\left[\left(1+r^{n}\right)(1-\gamma)+\frac{\pi_{1} \theta k^{n}}{1+\gamma}+\frac{\theta+1}{s_{r}} k^{n}-1\right]^{2}+4\left(\pi_{1}+\frac{1+\gamma-s_{k}}{s_{r}}\right) \frac{\theta k^{n}}{1+\gamma}>0
$$

$\lambda^{+}$and $\lambda^{-}$are given by

$\lambda^{+}=1+\frac{\left(1+r^{n}\right)(1-\gamma)+\frac{\pi_{1} \theta k^{n}}{1+\gamma}+\frac{\theta+1}{s_{r}} k^{n}-1+\sqrt{\left[\left(1+r^{n}\right)(1-\gamma)+\frac{\pi_{1} \theta k^{n}}{1+\gamma}+\frac{\theta+1}{s_{r}} k^{n}-1\right]^{2}+4\left(\pi_{1}+\frac{1+\gamma-s_{k}}{s_{r}}\right) \frac{\theta k^{n}}{1+\gamma}}}{2}$

and

$\lambda^{-}=1+\frac{\left(1+r^{n}\right)(1-\gamma)+\frac{\pi_{1} \theta k^{n}}{1+\gamma}+\frac{\theta+1}{s_{r}} k^{n}-1-\sqrt{\left[\left(1+r^{n}\right)(1-\gamma)+\frac{\pi_{1} \theta k^{n}}{1+\gamma}+\frac{\theta+1}{s_{r}} k^{n}-1\right]^{2}+4\left(\pi_{1}+\frac{1+\gamma-s_{k}}{s_{r}}\right) \frac{\theta k^{n}}{1+\gamma}}}{2}$.

It is straightforward to check that

$$
\lambda^{-}<1<\lambda^{+} \text {. }
$$


Let us denote by $\left(x^{+}, 1\right)^{\prime}$ and $\left(x^{-}, 1\right)^{\prime}$, the corresponding eigenvectors:

$$
\begin{aligned}
& x^{+}=\frac{\lambda^{+}-1}{\frac{\theta k^{n}}{1+\gamma}}>0, \\
& x^{-}=\frac{\lambda^{-}-1}{\frac{\theta k^{n}}{1+\gamma}}<0 .
\end{aligned}
$$

This shows that the normal steady state $\left(k^{n}, 1\right)$ is a saddle point.

Similarly, let $\widehat{q_{t}^{s}} \equiv\left(q_{t}-1\right)$ and $\widehat{k_{t}^{s}} \equiv\left(k_{t}-k^{s}\right)$. Then the linearized dynamic system around the speculative steady state can be written as:

$$
\begin{gathered}
\widehat{q_{t+1}^{s}}=\left[\left(1+r^{s}\right)(1-\gamma)+\left(\frac{\pi_{1} \theta}{1+\gamma}+\frac{\theta+1}{s_{r}}\right) k^{s}\right] \widehat{q_{t}^{s}}+\left[\pi_{1}+\frac{1+\gamma-s_{k}}{s_{r}}\right] \widehat{k_{t}^{s}} \\
\widehat{k_{t+1}^{s}}=\frac{\theta k^{s}}{1+\gamma} \widehat{q_{t}^{s}}+\widehat{k_{t}^{s}} .
\end{gathered}
$$

This system is characterized by the following $2 \times 2$ matrix:

$$
\Omega=\left[\begin{array}{cc}
\left(1+r^{s}\right)(1-\gamma)+\frac{\pi_{1} \theta k^{s}}{1+\gamma}+\frac{\theta+1}{s_{r}} k^{s} & \pi_{1}+\frac{1+\gamma-s_{k}}{s_{r}} \\
\frac{\theta k^{s}}{1+\gamma} & 1
\end{array}\right]
$$

The two eigenvalues $\lambda^{s+}$ and $\lambda^{s-}$ of $\Omega^{s}$ are real since the discriminant $D^{s}$ of $\operatorname{det}\left(\Omega^{s}-x I\right)$ is positive:

$$
D=\left[\left(1+r^{s}\right)(1-\gamma)+\frac{\pi_{1} \theta k^{s}}{1+\gamma}+\frac{\theta+1}{s_{r}} k^{s}-1\right]^{2}+4\left(\pi_{1}+\frac{1+\gamma-s_{k}}{s_{r}}\right) \frac{\theta k^{s}}{1+\gamma}>0 .
$$

$\lambda^{s+}$ and $\lambda^{s-}$ are given by

$\lambda^{s+}=1+\frac{\left(1+r^{s}\right)(1-\gamma)+\frac{\pi_{1} \theta k^{s}}{1+\gamma}+\frac{\theta+1}{s_{r}} k^{s}-1+\sqrt{\left[\left(1+r^{s}\right)(1-\gamma)+\frac{\pi_{1} \theta k^{s}}{1+\gamma}+\frac{\theta+1}{s_{r}} k^{s}-1\right]^{2}+4\left(\pi_{1}+\frac{1+\gamma-s_{k}}{s_{r}}\right) \frac{\theta k^{s}}{1+\gamma}}}{2}$

and

$\lambda^{s-}=1+\frac{\left(1+r^{s}\right)(1-\gamma)+\frac{\pi_{1} \theta k^{s}}{1+\gamma}+\frac{\theta+1}{s_{r}} k^{s}-1-\sqrt{\left[\left(1+r^{s}\right)(1-\gamma)+\frac{\pi_{1} \theta k^{s}}{1+\gamma}+\frac{\theta+1}{s_{r}} k^{s}-1\right]^{2}+4\left(\pi_{1}+\frac{1+\gamma-s_{k}}{s_{r}}\right) \frac{\theta k^{s}}{1+\gamma}}}{2}$.

It is straightforward to check that

$$
\lambda^{s-}<1<\lambda^{s+}
$$

Let us denote by $\left(x^{s+}, 1\right)^{\prime}$ and $\left(x^{s-}, 1\right)^{\prime}$, the corresponding eigenvectors:

$$
\begin{aligned}
& x^{s+}=\frac{\lambda^{s+}-1}{\frac{\theta k^{s}}{1+\gamma}}>0, \\
& x^{s-}=\frac{\lambda^{s-}-1}{\frac{\theta k^{s}}{1+\gamma}}<0 .
\end{aligned}
$$


This shows that the speculative steady state $\left(k^{s}, 1\right)$ is a saddle point.

Let us now fix $k^{n}, s_{0}, s_{r}, \pi_{0}, \pi_{1}, \gamma$ and $\theta$, and let us vary $k^{0}$ and $\delta$ such that assumptions 0 and 1 are verified and $\left|k^{0}-k^{n}\right|>\varepsilon \delta$ for some $\varepsilon>0$.

As we do this, $k^{s}, x^{s+}, x^{s-}, \lambda^{s+}$ and $\lambda^{s-}$ also vary. These variables are all continuous functions of $\delta$, and do not depend on $k^{0}$ as long as assumptions 0 and 1 are verified. Let us denote them by $k^{s}(\delta), x^{s+}(\delta), x^{s-}(\delta), \lambda^{s+}(\delta)$ and $\lambda^{s-}(\delta)$. It is clear that $k^{s}(\delta)=k^{n}+O(\delta)$, $x^{s+}(\delta)=x^{+}+O(\delta), x^{s-}(\delta)=x^{-}+O(\delta), \lambda^{s+}(\delta)=\lambda^{+}+O(\delta)$ and $\lambda^{s-}(\delta)=\lambda^{-}+O(\delta)$.

We will prove the following result. If $\frac{\lambda^{+}-1}{1-\lambda^{-}}<\frac{k^{s}-k^{0}}{k^{0}-k^{n}}$, then a transition is possible for $\delta$ small enough, and that if $\frac{\lambda^{+}-1}{1-\lambda^{-}}>\frac{k^{s}-k^{0}}{k^{0}-k^{n}}$ then for $\delta$ small enough, no transition is possible.

Because the dynamic system we consider is twice continuously differentiable in the regions $k<k^{0}$ and $k>k^{0}$, the following results hold:

-there exists $\bar{\delta}>0$ such that for all $\delta<\bar{\delta}$, there exist continuously differentiable functions $q_{\delta}^{s-}:\left[k^{0}, k^{s}\right] \rightarrow\left[1,+\infty\left[\right.\right.$ and $q^{n+}:\left[k^{n}, k^{0}\right] \rightarrow[1,+\infty[$ such that the stable manifold of $\left(k^{s}(\delta), 1\right)$ is parameterized by $\left(k, q_{\delta}^{s-}(k)\right)$ in the region $k \in\left[k^{0}, k^{s}(\delta)\right]$, and the unstable manifold of $\left(k^{n}, 1\right)$ is parameterized by $\left(k, q^{n+}(k)\right)$ in the region $k \in\left[k^{n}, k^{0}\right]$.

-there exists $\bar{\delta}>\overline{\bar{\delta}}>0$ and $m>0$ such that for all $\delta<\overline{\bar{\delta}}$ and $k \in\left[k^{0}, k^{s}(\delta)\right]$, and $k^{\prime} \in\left[k^{n}, k^{0}\right]$,

$$
\left|q_{\delta}^{s-}(k)-1-x^{s-}(\delta)\left(k-k^{s}(\delta)\right)\right|<m \delta^{2}
$$

and

$$
\left|q^{n+}\left(k^{\prime}\right)-1-x^{+}\left(k-k^{n}\right)\right|<m \delta^{2} .
$$

Using the fact that $k^{s}(\delta)=k^{n}+O(\delta), x^{s+}(\delta)=x^{+}+O(\delta), x^{s-}(\delta)=x^{-}+O(\delta)$, $\lambda^{s+}(\delta)=\lambda^{+}+O(\delta)$ and $\lambda^{s-}(\delta)=\lambda^{-}+O(\delta)$, we see that there exists $\overline{\bar{\delta}}>\overline{\bar{\delta}}>0$ and $M>0$ such that for all $\delta<\overline{\bar{\delta}}$ and $k \in\left[k^{0}, k^{s}(\delta)\right]$, and $k^{\prime} \in\left[k^{n}, k^{0}\right]$,

$$
\left|q_{\delta}^{s-}(k)-1-x^{-}\left(k-k^{s}(\delta)\right)\right|<M \delta^{2}
$$

and

$$
\left|q^{n+}\left(k^{\prime}\right)-1-x^{+}\left(k-k^{n}\right)\right|<M \delta^{2} .
$$

The condition for a transition from the normal steady state to the speculative steady state to be possible is that the intersection of the unstable arm of the normal steady state 
with the vertical $k=k_{0}$ line lies below the intersection of stable arm (the saddle path) of the speculative steady state with the vertical $k=k_{0}$ line.

The $q=1+x^{+}\left(k-k^{n}\right)$ line intersects the $k=k^{0}$ line at the point $\left(k^{0}, 1+x^{+}\left(k^{0}-k^{n}\right)\right)$. Similarly the $q=1+x^{-}\left(k-k^{s}(\delta)\right)$ line intersects the $k=k^{0}$ line at the point $\left(k^{0}, 1+x^{-}\left(k^{0}-\right.\right.$ $\left.\left.k^{s}(\delta)\right)\right)$. Therefore, if $\delta<\overline{\bar{\delta}}$, a necessary condition for the intersection of the unstable arm of the normal steady state with the vertical $k=k_{0}$ line to lie below the intersection of stable arm (the saddle path) of the speculative steady state with the vertical $k=k_{0}$ line is

$$
1+x^{-}\left(k^{0}-k^{s}(\delta)\right)+M \delta^{2}>1+x^{+}\left(k-k^{n}\right)-M \delta^{2} .
$$

Similarly, a sufficient condition is

$$
1+x^{-}\left(k^{0}-k^{s}(\delta)\right)-M \delta^{2}>1+x^{+}\left(k-k^{n}\right)+M \delta^{2} .
$$

We can rewrite (26) and (27) as

$$
\frac{\lambda^{+}-1}{1-\lambda^{-}}<\frac{k^{s}-k^{0}}{k^{0}-k^{n}}+\frac{2 M \delta^{2}}{k^{0}-k^{n}}
$$

and

$$
\frac{\lambda^{+}-1}{1-\lambda^{-}}<\frac{k^{s}-k^{0}}{k^{0}-k^{n}}-\frac{2 M \delta^{2}}{k^{0}-k^{n}}
$$

Using the fact that we have kept $k^{0}-k^{n}>\varepsilon \delta$, we see that a necessary condition for a transition when $\delta<\overline{\bar{\delta}}$ is

$$
\frac{\lambda^{+}-1}{1-\lambda^{-}}<\frac{k^{s}-k^{0}}{k^{0}-k^{n}}+\frac{2 M \delta}{\varepsilon}
$$

and that a sufficient condition for a transition is

$$
\frac{\lambda^{+}-1}{1-\lambda^{-}}<\frac{k^{s}-k^{0}}{k^{0}-k^{n}}-\frac{2 M \delta}{\varepsilon}
$$

Notice that $\frac{2 M \delta}{\varepsilon} \rightarrow 0$ when $\delta \rightarrow 0$.

This shows that if $\frac{\lambda^{+}-1}{1-\lambda^{-}}<\frac{k^{s}-k^{0}}{k^{0}-k^{n}}$, then a transition is possible for $\delta$ small enough, and that if $\frac{\lambda^{+}-1}{1-\lambda^{-}}>\frac{k^{s}-k^{0}}{k^{0}-k^{n}}$ then for $\delta$ small enough, no transition is possible. Let us now reexamine this condition.

We have that 


$$
\begin{aligned}
\frac{\lambda^{+}-1}{1-\lambda^{-}} & =-1+2 \frac{1}{1-\frac{1}{\sqrt{1+\frac{4\left(\pi_{1}+\frac{1+\gamma-s_{k}}{s}\right) \frac{\theta k^{n}}{1+\gamma}}{\left[\left(1+r^{n}\right)(1-\gamma)+\frac{\pi_{1} \theta k^{n}}{1+\gamma}+\frac{\theta+1}{s_{r}} k^{n}-1\right]^{2}}}}} \\
& =\Lambda(\theta) .
\end{aligned}
$$

$\Lambda$ is a decreasing function of

$$
\Upsilon \equiv \frac{4\left(\pi_{1}+\frac{1+\gamma-s_{k}}{s_{r}}\right) \frac{\theta k^{n}}{1+\gamma}}{\left[\left(1+r^{n}\right)(1-\gamma)+\frac{\pi_{1} \theta k^{n}}{1+\gamma}+\frac{\theta+1}{s_{r}} k^{n}-1\right]^{2}}
$$

$\Upsilon$ is non-monotonic in $\theta$. It is increasing in the interval $(0, \widetilde{\theta})$ and decreasing in the interval $(\widetilde{\theta},+\infty)$, where

$$
\widetilde{\theta}=\frac{\frac{k^{n}}{s_{r}}+\left(1+r^{n}\right)(1-\gamma)-1}{\left(\frac{\pi_{1}}{1+\gamma}+\frac{1}{s_{r}}\right) k^{n}} .
$$

In addition $\lim _{\theta \rightarrow 0} \Upsilon=0$, and $\lim _{\theta \rightarrow+\infty} \Upsilon=0$. As a result, $\Lambda$ is non-monotonic in $\theta$. It is decreasing on $(0, \widetilde{\theta})$ and increasing on $(\widetilde{\theta},+\infty)$, and reaches a minimum for $\theta=\widetilde{\theta}$. In addition, we have $\lim _{\theta \rightarrow 0} \Lambda=+\infty$ and $\lim _{\theta \rightarrow+\infty} \Lambda=+\infty$.

Q.E.D.

This shows that if $\frac{\lambda^{+}-1}{1-\lambda^{-}}<\frac{k^{s}-k^{0}}{k^{0}-k^{n}}$, then a transition is possible for $\delta$ small enough, and that if $\frac{\lambda^{+}-1}{1-\lambda^{-}}>\frac{k^{s}-k^{0}}{k^{0}-k^{n}}$ then for $\delta$ small enough, no transition is possible. In the rest of the appendix, we will often have to go through a similar argument. We will not go through the same details and instead state directly the equivalent of the condition $\frac{\lambda^{+}-1}{1-\lambda^{-}}>\frac{k^{s}-k^{0}}{k^{0}-k^{n}}$. The only exception concerns the discussion of bubbles where more complex issues arise.

\section{Proof of Proposition 3:}

The condition for a transition from the speculative steady state to the normal steady state to be possible is that the intersection of the unstable arm of the speculative steady state with the vertical $k=k_{0}$ line lies above the intersection of stable arm (the saddle path) of the normal steady state with the vertical $k=k_{0}$ line.

Going through the same arguments as in the proof of proposition 2, the condition for a transition for $\delta$ small enough and $k^{s}-k^{0}>\varepsilon^{\prime} \delta$ can be expressed as:

$$
\Lambda(\theta)=\frac{\lambda^{+}-1}{1-\lambda^{-}}<\frac{k^{0}-k^{n}}{k^{s}-k^{0}}
$$

Q.E.D. 


\section{B Proof of Propositions in Section 3}

\section{Proof of Proposition 4:}

In principle, there could be a third steady state once bubbles are feasible: $\left(k^{b}, 1, b\right)$, where $\pi_{0}-\pi_{1} k^{b}=\gamma$ and $b>0$. Assumption 4 guarantees that this steady state does not exist. To see why, assume the contrary. It is clear from assumption 4 that $k^{b}<k^{0}$. But the associated bubble in this steady state would be negative, since $b=s_{0}+s_{r} \pi_{0}-\Delta k^{b}<s_{0}+s_{r} \pi_{0}-\Delta k^{n}=0$, which is a contradiction.

In the proof of this proposition, we have to perform two linearizations, one around the normal steady state and one around the speculative steady state. This is because the characteristics of the dynamic system are different around the two steady states. The normal steady state has a two-dimensional unstable manifold and a one-dimensional stable manifold, whereas the speculative steady state has a one-dimensional unstable manifold and a two-dimensional stable manifold.

We consider the possibility of a small initial bubbles, $0<b_{0}<M_{b} \delta$ for some $M_{b}>0$, and show that if $\frac{\lambda^{+}-1}{1-\lambda^{-}}<\frac{k^{s}-k^{0}}{k^{0}-k^{n}}$, then there exists $m_{b}>0$ such that a transition is possible for $\delta$ small enough and $0<b_{0}<m_{b} \delta$, and that if $\frac{\lambda^{+}-1}{1-\lambda^{-}}>\frac{k^{s}-k^{0}}{k^{0}-k^{n}}$ then for $\delta$ small enough, for every $\widetilde{m_{b}}>0$, there exists $0<b_{0}<\widetilde{m_{b}} \delta$ such that no transition is possible with initial bubble $b_{0}$.

Let us first linearize the system around the normal steady state. Up to second order terms in $\widehat{q_{t}}=\left(q_{t}-1\right), \widehat{k_{t}}=\left(k_{t}-k^{n}\right), \widehat{r_{t}}=\left(r_{t}-r^{n}\right), \widehat{b_{t}}=b_{t}$ and $\delta$ we have that

$$
\begin{aligned}
\widehat{r_{t}} & =\frac{\theta+1}{s_{r}} k^{n} \widehat{q_{t}}+\frac{1+\gamma-s_{k}}{s_{r}} \widehat{k_{t}}+\frac{1}{s_{r}} \widehat{b_{t}}, \\
\widehat{q_{t+1}} & =\left[\left(1+r^{n}\right)(1-\gamma)+\frac{\pi_{1} \theta k^{n}}{1+\gamma}+\frac{\theta+1}{s_{r}} k^{n}\right] \widehat{q_{t}}+\left[\pi_{1}+\frac{1+\gamma-s_{k}}{s_{r}}\right] \widehat{k_{t}}+\frac{1}{s_{r}} \widehat{b_{t}}, \\
\widehat{k_{t+1}} & =\frac{\theta k^{n}}{1+\gamma} \widehat{q_{t}}+\widehat{k_{t}}, \\
\widehat{b_{t+1}} & =\frac{1+r^{n}}{1+\gamma} \widehat{b_{t}} .
\end{aligned}
$$

Similarly, we linearize the system around the speculative steady state. Up to second order terms in $\widehat{q_{t}}=\left(q_{t}-1\right), \widehat{k_{t}}=\left(k_{t}-k^{s}\right), \widehat{r_{t}}=\left(r_{t}-r^{s}\right), \widehat{b_{t}}=b_{t}$ and $\delta$, we have that 


$$
\begin{aligned}
\widehat{r_{t}} & =\frac{\theta+1}{s_{r}} k^{s} \widehat{q_{t}}+\frac{1+\gamma-s_{k}}{s_{r}} \widehat{k_{t}}+\frac{1}{s_{r}} \widehat{b_{t}}, \\
\widehat{q_{t+1}} & =\left[\left(1+r^{n}\right)(1-\gamma)+\frac{\pi_{1} \theta k^{s}}{1+\gamma}+\frac{\theta+1}{s_{r}} k^{s}\right] \widehat{q_{t}}+\left[\pi_{1}+\frac{1+\gamma-s_{k}}{s_{r}}\right] \widehat{k_{t}}+\frac{1}{s_{r}} \widehat{b_{t}}, \\
\widehat{k_{t+1}} & =\frac{\theta k^{s}}{1+\gamma} \widehat{q_{t}}+\widehat{k_{t}}, \\
\widehat{b_{t+1}} & =\frac{1+r^{s}}{1+\gamma} \widehat{b_{t}} .
\end{aligned}
$$

The dynamic system around the normal steady state is characterized by the matrix

$$
\Omega^{n}=\left[\begin{array}{ccc}
\left(1+r^{n}\right)(1-\gamma)+\frac{\pi_{1} \theta k^{n}}{1+\gamma}+\frac{\theta+1}{s_{r}} k^{n} & \pi_{1}+\frac{1+\gamma-s_{k}}{s_{r}} & \frac{1}{e} \\
\frac{\theta k^{n}}{1+\gamma} & 1 & 0 \\
0 & 0 & \frac{1+r^{n}}{1+\gamma}
\end{array}\right] .
$$

Similarly, the dynamic system around the speculative steady state is characterized by the matrix

$$
\Omega^{s}=\left[\begin{array}{ccc}
\left(1+r^{s}\right)(1-\gamma)+\frac{\pi_{1} \theta k^{s}}{1+\gamma}+\frac{\theta+1}{s_{r}} k^{s} & \pi_{1}+\frac{1+\gamma-s_{k}}{s_{r}} & \frac{1}{e} \\
\frac{\theta k^{s}}{1+\gamma} & 1 & 0 \\
0 & 0 & \frac{1+r^{s}}{1+\gamma}
\end{array}\right] .
$$

Keeping the same notations as above, it is clear that the eigenvalues of $\Omega^{n}$ are $\lambda^{n+}>1$, $\lambda^{n-}<1$ and $\frac{1+r^{n}}{1+\gamma}>1$, with corresponding eigenvectors $\left(x^{n+}, 1,0\right)^{\prime},\left(x^{n-}, 1,0\right)^{\prime}$ and $(0,0,1)$ where

$$
\lambda^{n+}=1+\frac{\left(1+r^{n}\right)(1-\gamma)+\frac{\pi_{1} \theta k^{n}}{1+\gamma}+\frac{\theta+1}{s_{r}} k^{n}-1+\sqrt{\left[\left(1+r^{n}\right)(1-\gamma)+\frac{\pi_{1} \theta k^{n}}{1+\gamma}+\frac{\theta+1}{s_{r}} k^{n}-1\right]^{2}+4\left(\pi_{1}+\frac{1+\gamma-s_{k}}{s_{r}}\right) \frac{\theta k^{n}}{1+\gamma}}}{2}
$$

and

$$
\lambda^{n-}=1+\frac{\left(1+r^{n}\right)(1-\gamma)+\frac{\pi_{1} \theta k^{n}}{1+\gamma}+\frac{\theta+1}{s_{r}} k^{n}-1-\sqrt{\left[\left(1+r^{n}\right)(1-\gamma)+\frac{\pi_{1} \theta k^{n}}{1+\gamma}+\frac{\theta+1}{s_{r}} k^{n}-1\right]^{2}+4\left(\pi_{1}+\frac{1+\gamma-s_{k}}{s_{r}}\right) \frac{\theta k^{n}}{1+\gamma}}}{2} .
$$

Therefore, the tangent plane to the unstable manifold of the normal steady state is the plane through the normal steady state with directing vectors $\left(x^{n+}, 1,0\right)^{\prime}$ and $(0,0,1)$, and the tangent line to its stable manifold is the line through the normal steady state with directing vector $\left(x^{n-}, 1,0\right)^{\prime}$.

Similarly, the eigenvalues of $\Omega^{s}$ are $\lambda^{s+}>1, \lambda^{s-}<1$ and $\frac{1+r^{s}}{1+\gamma}<1$, with corresponding eigenvectors $\left(x^{s+}, 1,0\right)^{\prime},\left(x^{s-}, 1,0\right)^{\prime}$ and $(0,0,1)$ where

$$
\lambda^{s+}=1+\frac{\left(1+r^{s}\right)(1-\gamma)+\frac{\pi_{1} \theta k^{s}}{1+\gamma}+\frac{\theta+1}{s_{r}} k^{s}-1+\sqrt{\left[\left(1+r^{s}\right)(1-\gamma)+\frac{\pi_{1} \theta k^{s}}{1+\gamma}+\frac{\theta+1}{s_{r}} k^{s}-1\right]^{2}+4\left(\pi_{1}+\frac{1+\gamma-s_{k}}{s_{r}}\right) \frac{\theta k^{s}}{1+\gamma}}}{2}
$$

and

$$
\lambda^{s-}=1+\frac{\left(1+r^{s}\right)(1-\gamma)+\frac{\pi_{1} \theta k^{s}}{1+\gamma}+\frac{\theta+1}{s_{r}} k^{s}-1-\sqrt{\left[\left(1+r^{s}\right)(1-\gamma)+\frac{\pi_{1} \theta k^{s}}{1+\gamma}+\frac{\theta+1}{s_{r}} k^{s}-1\right]^{2}+4\left(\pi_{1}+\frac{1+\gamma-s_{k}}{s_{r}}\right) \frac{\theta k^{s}}{1+\gamma}}}{2} .
$$


Therefore, the tangent line to the unstable manifold of the speculative steady state is the line through the speculative steady state with directing vectors $\left(x^{s+}, 1,0\right)^{\prime}$, and the tangent plane to its stable manifold is the plane through the speculative steady state with directing vectors $\left(x^{s-}, 1,0\right)^{\prime}$ and $(0,0,1)$.

Let us now vary $\delta, k^{0}=k^{0}(\delta) \gamma=\gamma(\delta)$ and $s^{0}=s^{0}(\delta)$ in such a way that $k^{n}=$ $\frac{s_{0}+s_{r} \pi_{0}}{s_{r} \pi_{1}+\left(1+\gamma-s_{k}\right)}$ is fixed, assumptions 0,1 and 4 are verified and $\left|k^{0}-k^{n}\right|>\varepsilon \delta$ for some $\varepsilon>0$. Note that $\gamma(\delta)<r^{n}=\pi_{0}-\pi_{1} k^{n}$ for $\delta>0$ and $\lim _{\delta \rightarrow 0} \gamma(\delta)=r^{n}=\pi_{0}-\pi_{1} k^{n}$. Also $k^{0}(\delta)>k^{n}$ for $\delta>0$ and $\lim _{\delta \rightarrow 0} k^{0}(\delta)=k^{n}$.

As we do this, $k^{s}, x^{n+}, x^{n-}, \lambda^{n+}, \lambda^{n-}, x^{s+}, x^{s-}, \lambda^{s+}$ and $\lambda^{s-}$ also vary. These variables are all continuous functions of $\delta$. Let us denote them by $k^{s}(\delta), x^{n+}(\delta), x^{n-}(\delta)$, $\lambda^{n+}(\delta), \lambda^{n-}(\delta), x^{s+}(\delta), x^{s-}(\delta), \lambda^{s+}(\delta)$ and $\lambda^{s-}(\delta)$. It is clear that $k^{s}(\delta)=k^{n}+O(\delta)$, $x^{n+}(\delta)=x^{+}+O(\delta), x^{n-}(\delta)=x^{-}+O(\delta), \lambda^{n+}(\delta)=\lambda^{+}+O(\delta), \lambda^{n-}(\delta)=\lambda^{-}+O(\delta), x^{s+}(\delta)=$ $x^{+}+O(\delta), x^{s-}(\delta)=x^{-}+O(\delta), \lambda^{s+}(\delta)=\lambda^{+}+O(\delta)$ and $\lambda^{s-}(\delta)=\lambda^{-}+O(\delta)$, with

$$
\begin{aligned}
& \lambda^{+}=1+\frac{\left(1+r^{n}\right)\left(1-r^{n}\right)+\frac{\pi_{1} \theta k^{n}}{1+r^{n}}+\frac{\theta+1}{s_{r}} k^{n}-1+\sqrt{\left[\left(1+r^{n}\right)\left(1-r^{n}\right)+\frac{\pi_{1} \theta k^{n}}{1+r^{n}}+\frac{\theta+1}{s_{r}} k^{n}-1\right]^{2}+4\left(\pi_{1}+\frac{1+r^{n}-s_{k}}{s_{r}}\right) \frac{\theta k^{n}}{1+r^{n}}}}{2}, \\
& \lambda^{-}=1+\frac{\left(1+r^{n}\right)\left(1-r^{n}\right)+\frac{\pi_{1} \theta k^{n}}{1+r^{n}}+\frac{\theta+1}{s_{r}} k^{n}-1-\sqrt{\left[\left(1+r^{n}\right)\left(1-r^{n}\right)+\frac{\pi_{1} \theta k^{n}}{1+r^{n}}+\frac{\theta+1}{s_{r}} k^{n}-1\right]^{2}+4\left(\pi_{1}+\frac{1+r^{n}-s_{k}}{s_{r}}\right) \frac{\theta k^{n}}{1+r^{n}}}}{2}, \\
& x^{+}=\frac{\lambda^{+}-1}{\frac{\theta k^{n}}{1+r^{n}}}>0, x^{-}=\frac{\lambda^{-}-1}{\frac{\theta k^{n}}{1+r^{n}}}<0 .
\end{aligned}
$$

Because the dynamic system we consider is twice continuously differentiable in the regions $k<k^{0}$ and $k>k^{0}$, the following results are true:

-there exists $\bar{\delta}>0$ such that for all $\delta<\bar{\delta}$, there exist continuously differentiable functions $q_{\delta}^{s-}:\left[k^{0}, k^{s}\right] \times\left[0, M_{b} \delta\right] \rightarrow\left[1,+\infty\left[\right.\right.$ and $q^{n+}:\left[k^{n}, k^{0}\right] \times\left[0, M_{b} \delta\right] \rightarrow[1,+\infty[$ such that the stable manifold of $\left(k^{s}(\delta), 1,0\right)$ is parameterized by $\left(k, b, q_{\delta}^{s-}(k, b)\right)$ in the region $(k, b) \in\left[k^{0}, k^{s}(\delta)\right] \times\left[0, M_{b} \delta\right]$, and the unstable manifold of $\left(k^{n}, 1,0\right)$ is parameterized by $\left(k, b, q_{\delta}^{n+}(k)\right)$ in the region $(k, b) \in\left[k^{n}, k^{0}\right] \times\left[0, M_{b} \delta\right]$.

-there exists $\bar{\delta}>\overline{\bar{\delta}}>0$ and $m>0$ such that for all $\delta<\overline{\bar{\delta}},(k, b) \in\left[k^{0}, k^{s}(\delta)\right] \times\left[0, M_{b} \delta\right]$, and $\left(k^{\prime}, b^{\prime}\right) \in\left[k^{n}, k^{0}\right] \times\left[0, M_{b} \delta\right]$

$$
\left|q_{\delta}^{s-}(k, b)-1-x^{s-}(\delta)\left(k-k^{s}(\delta)\right)\right|<m \delta^{2}
$$

and

$$
\left|q_{\delta}^{n+}\left(k^{\prime}, b^{\prime}\right)-1-x^{n+}(\delta)\left(k-k^{n}\right)\right|<m \delta^{2} .
$$

Using the fact that $k^{s}(\delta)=k^{n}+O(\delta), x^{s-}(\delta)=x^{-}+O(\delta), x^{n+}(\delta)=x^{+}+O(\delta)$, $\lambda^{s-}(\delta)=\lambda^{-}+O(\delta)$ and $\lambda^{n+}(\delta)=\lambda^{+}+O(\delta)$, we see that there exists $\overline{\bar{\delta}}>\overline{\bar{\delta}}>0$ and $M>0$ 
such that for all $\delta<\overline{\bar{\delta}},(k, b) \in\left[k^{0}, k^{s}(\delta)\right] \times\left[0, M_{b} \delta\right]$, and $\left(k^{\prime}, b^{\prime}\right) \in\left[k^{n}, k^{0}\right] \times\left[0, M_{b} \delta\right]$,

$$
\left|q_{\delta}^{s-}(k, b)-1-x^{-}\left(k-k^{s}(\delta)\right)\right|<M \delta^{2}
$$

and

$$
\left|q_{\delta}^{n+}\left(k^{\prime}, b^{\prime}\right)-1-x^{+}\left(k-k^{n}\right)\right|<M \delta^{2} .
$$

The $q=1+x^{+}\left(k-k^{n}\right)$ plane intersects the $k=k^{0}$ plane along the line $k=k^{0}, q=$ $1+x^{+}\left(k^{0}-k^{n}\right)$. Similarly the $q=1+x^{-}\left(k-k^{s}(\delta)\right)$ plane intersects the $k=k^{0}$ plane along the line $k=k^{0}, q=1+x^{-}\left(k^{0}-k^{s}(\delta)\right)$. Therefore, if $\delta<\overline{\bar{\delta}}$, we have that

$$
1+x^{-}\left(k^{0}-k^{s}(\delta)\right)+M \delta^{2}>1+x^{+}\left(k-k^{n}\right)-M \delta^{2} .
$$

is a necessary condition for the intersection of the unstable manifold of the normal steady state with the vertical $k=k_{0}$ plane to lie below the intersection of stable manifold of the speculative steady state with the vertical $k=k_{0}$ plane in the region $b \in\left[0, M_{b} \delta\right]$.

Similarly, a sufficient condition is

$$
1+x^{-}\left(k^{0}-k^{s}(\delta)\right)-M \delta^{2}>1+x^{+}\left(k-k^{n}\right)+M \delta^{2} .
$$

We can rewrite (28) and (29) as

$$
\frac{\lambda^{+}-1}{1-\lambda^{-}}<\frac{k^{s}-k^{0}}{k^{0}-k^{n}}+\frac{2 M \delta^{2}}{k^{0}-k^{n}}
$$

and

$$
\frac{\lambda^{+}-1}{1-\lambda^{-}}<\frac{k^{s}-k^{0}}{k^{0}-k^{n}}-\frac{2 M \delta^{2}}{k^{0}-k^{n}}
$$

Using the fact that $k^{0}-k^{n}>\varepsilon \delta$, we see that a necessary condition for a transition when $\delta<\overline{\bar{\delta}}$ is

$$
\frac{\lambda^{+}-1}{1-\lambda^{-}}<\frac{k^{s}-k^{0}}{k^{0}-k^{n}}+\frac{2 M \delta}{\varepsilon}
$$

and that a sufficient condition for a transition is

$$
\frac{\lambda^{+}-1}{1-\lambda^{-}}<\frac{k^{s}-k^{0}}{k^{0}-k^{n}}-\frac{2 M \delta}{\varepsilon} .
$$


Notice that $\frac{2 M \delta}{\varepsilon} \rightarrow 0$ when $\delta \rightarrow 0$.This shows that if $\frac{\lambda^{+}-1}{1-\lambda^{-}}<\frac{k^{s}-k^{0}}{k^{0}-k^{n}}$, then there exists $m_{b}>0$ such that a transition is possible for $\delta$ small enough and $0<b_{0}<m_{b} \delta$, and that if

$\frac{\lambda^{+}-1}{1-\lambda^{-}}>\frac{k^{s}-k^{0}}{k^{0}-k^{n}}$ then for $\delta$ small enough, for every $\widetilde{m_{b}}>0$, there exists $0<b_{0}<\widetilde{m_{b}} \delta$ such that no transition is possible with initial bubble $b_{0}$.

This condition holds if and only if

$$
\Lambda=\frac{\lambda^{+}-1}{1-\lambda^{-}}<\frac{k^{n}-k^{0}}{k^{0}-k^{s}}
$$

which is exactly the same condition as without bubbles. The discussion of the possibility of a transition is therefore entirely similar.

Q.E.D.

\section{Proof of Proposition 5:}

It is also clear that the projection of the trajectory of the transition path with initial bubble $b_{0}>0$ on the plane $b=0$ will lie below the trajectory of the transition path with zero initial bubble. To see this, note that the projection of a trajectory with positive bubble can only cross the projection of a trajectory with zero bubble from below. This proves the claim since the projection of a transition path, with or without bubble ends in the speculative steady state $\left(k^{s}, 1,0\right)$.

By the capital accumulation equation, this in turn implies that a transition path with initial bubble $b_{0}>0$ will reach every plane $k=h$ with $k^{n}<h \leq k^{s}$ after a larger number of periods than the transition path with zero initial bubble.

Q.E.D.

\section{Proof of Propositions in Section 4}

\section{C.1 Fiscal}

We can rewrite the capital market equilibrium condition as

$$
s\left((1-\bar{\tau}) w\left(k_{t}\right), r_{t}\right)+\bar{\tau} w\left(k_{t}\right)-\bar{g}_{t}=\left(q_{t}+x_{t}+\frac{1}{2} \theta^{-1}\left(x_{t}-\gamma\right)^{2}\right) k_{t}+d_{t},
$$

where

$$
\bar{g}_{t}=\bar{g}+\alpha\left(w_{t}-w^{n}\right) .
$$

Let us define a net saving function 


$$
\widetilde{s}\left(w\left(k_{t}\right), r_{t}\right)=s\left((1-\bar{\tau}) w\left(k_{t}\right), r_{t}\right)+\bar{\tau} w\left(k_{t}\right)-\bar{g}_{t} .
$$

In this proposition, we perform a comparative statics exercise varying $\alpha$ (or equivalently $\bar{g}_{t}$ ) and keeping the normal steady state fixed. Therefore, let us denote by $s_{k}=$ $\frac{\partial s\left((1-\bar{\tau}) w\left(k_{t}\right), r_{t}\right)+\bar{\tau} w\left(k_{t}\right)-\bar{g}}{\partial k_{t}}$ and $s_{r}=\frac{\partial s\left((1-\bar{\tau}) w\left(k_{t}\right), r_{t}\right)+\bar{\tau} w\left(k_{t}\right)-\bar{g}}{\partial r_{t}}$. These numbers do not depend on $\alpha$.

Note that a first order approximation of wages around the normal steady state is:

$$
w\left(k_{t}\right)=w^{n}+\pi_{1} k^{n} \widehat{k_{t}} .
$$

We therefore have the following first order approximation for the net saving function

$$
\widetilde{s}\left(w\left(k_{t}\right), r_{t}\right)= \begin{cases}s_{k}^{\alpha} k_{t}+s_{r} r_{t}+s_{0}^{\alpha}, & k<k^{o} ; \\ s_{k}^{\alpha} k_{t}+s_{r} r_{t}+s_{0}^{\alpha}+\delta, & k \geq k^{o},\end{cases}
$$

where $s_{k}^{\alpha}=s_{k}-\alpha \pi_{1} k^{n}$, and $s_{0}^{\alpha}=s_{0}+\frac{\alpha \pi_{1}\left(k^{n}\right)^{2}}{s_{r}}$.

Assumption 4 guarantees that the normal steady state is in a dynamically efficient region, while the speculative steady state, if it exists, is in a dynamically inefficient region.

The speculative steady state, if it exists, is characterized by the following equations

$$
\begin{gathered}
k^{s}>k^{0}, \\
\widetilde{s}\left(w\left(k^{s}\right), r^{s}\right)=d^{s}+(1+\gamma) k^{s}, \\
r^{s}=\pi_{0}-\pi_{1} k^{s}, \\
d^{s}=\frac{1+r^{s}}{\gamma-r^{s}}\left(\bar{g}+\alpha\left(w^{s}-w^{n}\right)-\bar{\tau} w^{s}\right) .
\end{gathered}
$$

Similarly, in the normal steady state, we have

$$
\begin{gathered}
\widetilde{s}\left(w\left(k^{n}\right), r^{n}\right)=(1+\gamma) k^{n}, \\
r^{n}=\pi_{0}-\pi_{1} k^{n}, \\
\bar{g}=\bar{\tau} w^{n} .
\end{gathered}
$$


Using these equations, we can rewrite the conditions characterizing the speculative steady state as

$$
\begin{gathered}
k^{s}>k^{0} \\
s_{k}^{\alpha}\left(k^{s}-k^{n}\right)+s_{r}\left(r^{s}-r^{n}\right)+\delta=d^{s}+(1+\gamma)\left(k^{s}-k^{n}\right), \\
r^{s}-r^{n}=-\pi_{1}\left(k^{s}-k^{n}\right), \\
d^{s}=\frac{1+r^{s}}{\gamma-r^{s}}(\alpha-\bar{\tau})\left(w^{s}-w^{n}\right), \\
w^{s}-w^{n}=\pi_{1} k^{n}\left(k^{s}-k^{n}\right) .
\end{gathered}
$$

We can solve these equations for $k^{s}, w^{s}, r^{s}$ and $d^{s}$.

In particular, we get

$$
\left[s_{k}^{\alpha}-\pi_{1} s_{r}-(1+\gamma)\right]\left(k^{s}-k^{n}\right)+\delta=\frac{1+r^{n}-\pi_{1}\left(k^{s}-k^{n}\right)}{\gamma-r^{n}+\pi_{1}\left(k^{s}-k^{n}\right)}(\alpha-\bar{\tau}) \pi_{1} k^{n}\left(k^{s}-k^{n}\right) .
$$

We can rewrite this equation as

$\delta=\left[(1+\gamma)-s_{k}+\pi_{1} s_{r}\right]\left(k^{s}-k^{n}\right)+\alpha \pi_{1} k^{n}\left(k^{s}-k^{n}\right)+(\alpha-\bar{\tau}) \frac{\left[1+r^{n}-\pi_{1}\left(k^{s}-k^{n}\right)\right] \pi_{1} k^{n}\left(k^{s}-k^{n}\right)}{\gamma-r^{n}+\pi_{1}\left(k^{s}-k^{n}\right)}$.

Using the fact that $1+r^{s}=1+r^{n}-\pi_{1}\left(k^{s}-k^{n}\right)>0,(1+\gamma)-s_{k}-\pi_{1} s_{r}>0$ and $k^{s}>k^{0}$, we see that for $\alpha \geq \bar{\tau}$, the right hand side of this equation is greater than

$$
\left[(1+\gamma)-s_{k}+\pi_{1} s_{r}\right]\left(k^{0}-k^{n}\right)+\alpha \pi_{1} k^{n}\left(k^{0}-k^{n}\right)
$$

It is clear that

$$
\lim _{\alpha \rightarrow+\infty}\left\{\left[(1+\gamma)-s_{k}+\pi_{1} s_{r}\right]\left(k^{0}-k^{n}\right)+\alpha \pi_{1} k^{n}\left(k^{0}-k^{n}\right)\right\}=+\infty .
$$

This proves that for $\alpha$ high enough (30), has no solution.

We have the stronger result that a sufficient condition for (30) not to have a solution is

$$
\alpha \geq \max \left\{\frac{\Delta}{\pi_{1} k^{n}} \frac{\frac{\delta}{\Delta}}{\left(k^{0}-k^{n}\right)}\left(1-\frac{k^{0}-k^{n}}{\frac{\delta}{\Delta}}\right), \bar{\tau}\right\} .
$$


Therefore if $\frac{\Delta}{\pi_{1} k^{n}} \frac{\frac{\delta}{\Delta}}{\left(k^{0}-k^{n}\right)}\left(1-\frac{k^{0}-k^{n}}{\frac{\delta}{\Delta}}\right)<1$, it can be the case that there is no solution for $\alpha \geq \bar{\alpha}$ where $\bar{\alpha}<1$.

Q.E.D.

\section{C.2 External}

We continue to assume that $\delta$ is small so that we can make a first order approximation around $q=1$ and $k=k^{n}$ for the transition from $k^{n}$ to $k^{s}$, if such transition is possible. Let $\widehat{q_{t}} \equiv\left(q_{t}-1\right), \widehat{k_{t}} \equiv\left(k_{t}-k^{n}\right)$, and $z_{t}=\left(z_{t}-z_{t}^{n}\right)$ then the linearized dynamic system can be written as:

$\widehat{q_{t+1}}=\left[\left(1+r^{n}\right)(1-\gamma)+\left(\pi_{1} \theta+\widetilde{\pi_{1}}(1+\theta)\right) \frac{k^{n}}{1+\gamma}\right] \widehat{q_{t}}+\left[\pi_{1}+\widetilde{\pi_{1}} \frac{1+\gamma-s_{k}}{1+\gamma}\right] \widehat{k_{t}}-1\left\{\widehat{k_{t}} \geq \widehat{k^{o}}\right\} \frac{\widetilde{\pi_{1}} \delta}{1+\gamma}$

$$
\widehat{k_{t+1}}=\frac{\theta k^{n}}{1+\gamma} \widehat{q_{t}}+\widehat{k_{t}}
$$

The analysis and proofs that follow refer to the dynamic system described by (31) and $(32)$.

The speculative steady state is characterized by $\widehat{k^{s}}=\frac{\widetilde{\pi_{1}} \delta}{\pi_{1}(1+\gamma)+\pi_{1}\left(1+\gamma-s_{k}\right)}>0$ and $\widehat{z^{s}}=$ $\frac{\pi_{1} \delta}{\pi_{1}(1+\gamma)+\pi_{1}\left(1+\gamma-s_{k}\right)}>0$.

For a speculative growth path to exist, it must be the case that the unstable path of the normal steady state intersects the $k^{o}$ line below the intersection of the latter and the saddle path of the speculative steady state. We can express this condition as

$$
\Lambda^{e} \equiv \frac{\lambda^{e+}-1}{1-\lambda^{e-}}<\frac{k^{s}-k^{0}}{k^{0}-k^{n}}
$$

where the superscript $e$ stands for external and

$\lambda^{e+}=1+\frac{-1+\left(1+r^{n}\right)(1-\gamma)+\frac{\widetilde{\pi}_{1}(1+\theta) k^{n}}{1+\gamma}+\frac{\pi_{1} \theta k^{n}}{1+\gamma}+\sqrt{\left(-1+\left(1+r^{n}\right)(1-\gamma)+\frac{\widetilde{\pi}_{1}(1+\theta) k^{n}}{1+\gamma}+\frac{\pi_{1} \theta k^{n}}{1+\gamma}\right)^{2}+4 \frac{\widetilde{\pi}_{1} \theta k^{n}\left(1-\frac{s_{k}}{1+\gamma}\right)}{1+\gamma}+4 \frac{\pi_{1} \theta k^{n}}{1+\gamma}}}{2}$

and

$\lambda^{e-}=1+\frac{-1+\left(1+r^{n}\right)(1-\gamma)+\frac{\widetilde{\pi}_{1}(1+\theta) k^{n}}{1+\gamma}+\frac{\pi_{1} \theta k^{n}}{1+\gamma}-\sqrt{\left(-1+\left(1+r^{n}\right)(1-\gamma)+\frac{\widetilde{\pi}_{1}(1+\theta) k^{n}}{1+\gamma}+\frac{\pi_{1} \theta k^{n}}{1+\gamma}\right)^{2}+4 \frac{\widetilde{\pi}_{1} \theta k^{n}\left(1-\frac{s_{k}}{1+\gamma}\right)}{1+\gamma}+4 \frac{\pi_{1} \theta k^{n}}{1+\gamma}}}{2}$.

We have

$$
\Lambda^{e}=-1+2 \frac{1}{1-\frac{1}{\sqrt{1+\frac{4 \frac{\widetilde{\pi}_{1} \theta k^{n}\left(1-\frac{s_{k}}{1+\gamma}\right)}{1+\gamma}+4 \frac{\pi_{1} \theta k^{n}}{1+\gamma}}{\left[-1+\left(1+r^{n}\right)(1-\gamma)+\frac{\widetilde{\pi_{1}}(1+\theta) k^{n}}{1+\gamma}+\frac{\pi_{1} \theta k^{n}}{1+\gamma}\right]^{2}}}}}
$$


This is true because we have assumed that Assumption 0' holds, which implies that $-1+\left(1+r^{n}\right)(1-\gamma)+\frac{\widetilde{\pi_{1}} k^{n}}{1+\gamma}>0$ and therefore

$-1+\left(1+r^{n}\right)(1-\gamma)+\frac{\widetilde{\pi_{1}}(1+\theta) k^{n}}{1+\gamma}+\frac{\pi_{1} \theta k^{n}}{1+\gamma}>0$.

$\Lambda^{e}$ is a decreasing function of

$$
\Upsilon^{e} \equiv \frac{4 \frac{\widetilde{\pi_{1} \theta k^{n}\left(1-\frac{s_{k}}{1+\gamma}\right)}}{1+\gamma}+4 \frac{\pi_{1} \theta k^{n}}{1+\gamma}}{\left[-1+\left(1+r^{n}\right)(1-\gamma)+\frac{\widetilde{\pi_{1}}(1+\theta) k^{n}}{1+\gamma}+\frac{\pi_{1} \theta k^{n}}{1+\gamma}\right]^{2}}
$$

$\Upsilon^{e}$ is non-monotonic in $\theta$. It is increasing on $\left(0, \widetilde{\theta}^{e}\right)$ and decreasing on $\left(\widetilde{\theta}^{e},+\infty\right)$, where

$$
\widetilde{\theta}^{e}=\frac{-1+\left(1+r^{n}\right)(1-\gamma)+\frac{\widetilde{\pi_{1}} k^{n}}{1+\gamma}}{\frac{\left(\pi_{1}+\widetilde{\pi}_{1}\right) k^{n}}{1+\gamma}} .
$$

In addition $\lim _{\theta \rightarrow 0} \Upsilon^{e}=0$, and $\lim _{\theta \rightarrow+\infty} \Upsilon^{e}=0$.

As a result, $\Lambda^{e}$ is non-monotonic in $\theta$. It is decreasing on $\left(0, \widetilde{\theta}^{e}\right)$ and increasing on $\left(\widetilde{\theta}^{e},+\infty\right)$, and reaches a minimum for $\theta=\widetilde{\theta}^{e}$. In addition, we have $\lim _{\theta \rightarrow 0} \Lambda^{e}=+\infty$, and $\lim _{\theta \rightarrow+\infty} \Lambda^{e}=+\infty$.

Q.E.D.

\section{C.3 Technological progress}

Let us assume that $\delta_{p}=1-p$ is small so that we can make a first order approximation around $q=1$ and $k=k^{n}$ for the transition from $k^{n}$ to $k^{s}$, if such transition is possible. Let $\widehat{q_{t}} \equiv\left(q_{t}-1\right)$ and $\widehat{k_{t}} \equiv\left(k_{t}-k^{n}\right)$, then the linearized dynamic system can be written as:

$$
\begin{aligned}
& \widehat{q_{t+1}}= \begin{cases}{\left[\left(1+r^{n}\right)(1-\gamma)+\left(\frac{\pi_{1} \theta}{1+\gamma}+\frac{\theta+1}{s_{r}}\right) k^{n}\right] \widehat{q_{t}}+\frac{\Delta}{s_{r}} \widehat{k_{t}},} & k_{t}<k^{o} ; \\
\left.\left(1+r^{n}\right)(1-\gamma)+\left(\frac{\pi_{1} \theta}{1+\gamma}+\frac{\theta+1}{s_{r}}\right) k^{n}\right] \widehat{q_{t}}+\frac{\Delta}{s_{r}} \widehat{k_{t}}+\left[\left(1+r^{n}\right) \gamma-\frac{\pi_{1} \theta}{1+\gamma} k^{n}+\frac{\gamma-\theta}{s_{r}} k^{n}\right] \delta_{p}, & k \geq k^{o},\end{cases} \\
& \widehat{k_{t+1}}= \begin{cases}\frac{\theta k^{n}}{1+\gamma} \widehat{q_{t}}+\widehat{k_{t}}, & k_{t}<k^{o} \\
\frac{\theta k^{n}}{1+\gamma} \widehat{q_{t}}+\widehat{k_{t}}+\frac{\theta k^{n}}{1+\gamma} \delta_{p} & k \geq k^{o}\end{cases}
\end{aligned}
$$

The analysis and proofs that follow refer to the dynamic system described by (34) and $(35)$.

\section{Assumption 5 (Minimum technological progress):}

$$
\delta_{p}>\underline{\delta_{p}}=\frac{\frac{\Delta}{s_{r}}}{1+r^{n}+\frac{1+\gamma}{s_{r}} k^{n}}\left(k^{0}-k^{n}\right) .
$$




\section{Proposition 10 (Multiple Steady States)}

If Assumption 3 is satisfied, the economy has two non-degenerate steady states, $k^{n}$ and $k^{s}$, with:

$$
k^{n}=\frac{s_{0}+\pi_{0}}{\Delta}<k^{o}<k^{n}+\frac{1+r^{n}+(1+\gamma) k^{n} / s_{r}}{\Delta} \delta_{p}=k^{s},
$$

where $\Delta \equiv \pi_{1}+\left(1+\gamma-s_{k}\right) / s_{r}>0$, and the superscripts " $n$ " and "s" stand for normal and speculative, respectively.

\section{Assumption 6 (Speculative adjustment costs region):}

$$
\frac{\lambda^{+}-1+\frac{\frac{\Delta}{s_{r}} \frac{k^{n}}{1+\gamma}}{1+r^{n}+\frac{1+\gamma}{s_{r}} k^{n}} \theta}{1-\lambda^{-}-\frac{\frac{\Delta}{s_{r}} \frac{k^{n}}{1+\gamma}}{1+r^{n}+\frac{1+\gamma}{s_{r}} k^{n}} \theta}<\frac{k^{s}-k^{0}}{k^{0}-k^{n}} .
$$

\section{Proposition 11 (Multiple Equilibria and Speculative Growth)}

If Assumptions 5 and 6 hold, there is a speculative growth path that takes the economy from $k^{n}$ to $k^{s}$.

\section{Proof:}

Imposing $\widehat{q_{t+1}}=\widehat{q_{t}}$ and $\widehat{k_{t+1}}=\widehat{k_{t}}$ and solving for $\widehat{k^{s}}$ and $\widehat{q^{s}}$ in

$\widehat{q_{t+1}}=\left[\left(1+r^{n}\right)(1-\gamma)+\left(\frac{\pi_{1} \theta}{1+\gamma}+\frac{\theta+1}{s_{r}}\right) k^{n}\right] \widehat{q_{t}}+\frac{\Delta}{s_{r}} \widehat{k}_{t}+\left[\left(1+r^{n}\right) \gamma-\frac{\pi_{1} \theta}{1+\gamma} k^{n}+\frac{\gamma-\theta}{s_{r}} k^{n}\right] \delta_{p}$

and

$$
\widehat{k_{t+1}}=\frac{\theta k^{n}}{1+\gamma} \widehat{q_{t}}+\widehat{k_{t}}+\frac{\theta k^{n}}{1+\gamma} \delta_{p}
$$

we find that $\widehat{k^{s}}=\frac{1+r^{n}+\frac{1+\gamma}{s_{r}} k^{n}}{\frac{\Delta}{s_{r}}} \delta_{p}$ and $\widehat{q^{s}}=-\delta_{p}$. This is a steady state if and only if $\widehat{k^{s}}>\widehat{k^{0}}=k^{0}-k^{n}$, which we can rewrite as

$$
\delta_{p}>\underline{\delta_{p}}=\frac{\frac{\Delta}{s_{r}}}{1+r^{n}+\frac{1+\gamma}{s_{r}} k^{n}}\left(k^{0}-k^{n}\right) .
$$

Let us now assume that this inequality holds. We now ask under what conditions a transition from the normal steady state to the speculative steady state is possible. For a speculative growth path to exist, it must be the case that the unstable path of the normal steady state intersects the $k^{o}$ line below the intersection of the latter and the saddle path of the speculative steady state. We can express this condition as

$$
\frac{\lambda^{+}-1}{\frac{\theta k^{n}}{1+\gamma}}\left(k^{0}-k^{n}\right)<\frac{1-\lambda^{-}}{\frac{\theta k^{n}}{1+\gamma}}\left(k^{s}-k^{0}\right)-\delta_{p} .
$$


We can rewrite $(37)$ as

$$
\frac{\lambda^{+}-1+\frac{\frac{\Delta}{s_{r}} \frac{k^{n}}{1+\gamma}}{1+r^{n}+\frac{1+\gamma}{s_{r}} k^{n}} \theta}{1-\lambda^{-}-\frac{\frac{\Delta}{s_{r}} \frac{k^{n}}{1+\gamma}}{1+r^{n}+\frac{1+\gamma}{s_{r}} k^{n}} \theta}<\frac{k^{s}-k^{0}}{k^{0}-k^{n}} .
$$

Q.E.D.

\section{Proof of Claims in Section 5}

The curve $n_{t}=0$ intersects the $q=1$ line at a point $(1, k)$ if and only if

$$
\gamma=\mu \frac{w\left(k_{t}\right)-\bar{c}}{k_{t}}-\frac{f^{\prime}\left(k_{t}\right)}{1+r}
$$

We make the assumption that this equation has at least one solution. If we assume for example that $f\left(k_{t}\right)=A k_{t}^{\alpha}$, with $0<\alpha<1$ and $\mu(1+r)>\frac{\alpha}{1-\alpha}$ and $\bar{c}<\max _{k>0}\{\mu w(k)-$ $\left.\frac{f^{\prime}(k) k}{1+r}-\gamma k\right\}$, this assumption will be verified and the equation $n_{t}=0$ will have exactly two solutions.

Let $k^{0}<k^{1}$ be the two first intersections of this curve with the $q=1$ line $\left(k_{1}=+\infty\right.$ if there is no second intersection).

We assume that there are two steady states $k^{n}<k^{s}$ where $k^{n}<k^{0}$, and $k^{0}<k^{s}<k^{1}$.

Because in this framework it is now the interest rate in the normal steady state $r+\delta$ that depends on $\delta$, we will approximate the dynamics of the system around the speculative steady state (where the interest rate is $r$ ). Letting $\delta$ tend to 0 , we are moving the normal steady state while keeping the speculative steady state fixed.

Assumption 7: $\Delta \equiv s_{r} \pi_{1}+\left(1+\gamma-s_{k}\right)>0, k^{s} \equiv \frac{\pi_{0}-r}{\pi_{1}}>k^{0}$.

Assumption 8 (Minimum growth-funding feedback): $\delta>\underline{\delta} \equiv s_{r} \pi_{1}\left(k^{s}-k^{0}\right)$.

Assumption 9: $\quad(1+\mu) \pi_{1} k^{s}-\gamma-\frac{r}{1+r}>0$ and $(\theta+\gamma)-\frac{\pi_{1} \theta k^{s}}{1+\gamma}>0$.

The last assumption is made to make sure that locally, the $n=0$ curve is upward sloping line with the low interest rate region to its right.

Let

$$
\Xi_{t}=\left[\gamma+(\theta+\gamma)\left(q_{t}-1\right)+\theta\left(q_{t}-1\right)^{2}\right] k_{t}-\mu w\left(k_{t}\right)-\bar{c}+\frac{f^{\prime}\left(\frac{1+\gamma+\theta\left(q_{t}-1\right)}{1+\gamma} k_{t}\right)}{1+r} k_{t} .
$$

Assuming that $\delta$ and $n^{s}$ are small, let us perform a first order approximation around $q=q^{*}=1$ and $k=k^{s}$. 
Up to second order terms in $\widehat{q_{t}}=\left(q_{t}-1\right), \widehat{k_{t}}=\left(k_{t}-k^{s}\right), \widehat{k_{0}}=\left(k^{0}-k^{s}\right), \widehat{r_{t}}=\left(r_{t}-r^{s}\right)$, $\widehat{n_{t}}=n_{t}-n^{s}, \delta$ and $n^{s}$, we have:

$$
\begin{aligned}
\widehat{\Xi_{t}} & =\gamma \widehat{k_{t}}+(\theta+\gamma) k^{s} \widehat{q_{t}}-(1+\mu) \pi_{1} k^{s} \widehat{k_{t}}-\frac{\pi_{1} \theta k^{s 2}}{1+\gamma} \widehat{q_{t}}+\frac{r}{1+r} \widehat{k_{t}} \\
& =\left[(\theta+\gamma) k^{s}-\frac{\pi_{1} \theta k^{s 2}}{1+\gamma}\right] \widehat{q_{t}}-\left[(1+\mu) \pi_{1} k-\gamma-\frac{r}{1+r}\right] \widehat{k_{t}} .
\end{aligned}
$$

We have $\widehat{r_{t}}=0$ if $\widehat{\Xi_{t}} \leq-\Xi^{s}$ and $\widehat{r_{t}}=-\frac{\delta}{s_{r}}$ if $\widehat{\Xi_{t}}>-\Xi^{s}$. Note that by assumption,

$$
\begin{gathered}
\Xi^{s}=\gamma k^{s}-\mu\left(w^{s}-\bar{c}\right)+\frac{r}{1+r} k^{s}<0 \text { and } \widehat{k^{n}}=-\frac{\delta}{s_{r} \pi_{1}}<\widehat{k_{0}}<0 . \\
\widehat{q_{t+1}}=\left[\left(1+r^{s}\right)(1-\gamma)+\frac{\pi_{1} \theta k^{s}}{1+\gamma}\right] \widehat{q_{t}}+\pi_{1} \widehat{k_{t}}+1\left\{\widehat{\Xi_{t}} \leq-\Xi^{s}\right\} \frac{\delta}{s_{r}} \\
\widehat{k_{t+1}}=\frac{\theta k_{L}}{1+\gamma} \widehat{q_{t}}+\widehat{k_{t}} .
\end{gathered}
$$

The analysis and proofs that follow refer to the dynamic system described by (38) and (39).

For a speculative growth path to exist two conditions must be satisfied. First, it must be the case that the unstable arm of the normal steady state is less steep than the $\widehat{\Xi_{t}}=-\Xi^{s}$ line. Second it must be the case that the unstable arm of the normal steady state intersects the $\widehat{\Xi}_{t}=-\Xi^{s}$ line below the intersection of the latter and the saddle path of the speculative equilibrium. We can express these conditions as

$$
\begin{aligned}
& \Psi^{f} \equiv \frac{(1+\mu) \pi_{1} k^{s}-\gamma-\frac{r}{1+r}}{(1+\gamma)\left(1+\frac{\gamma}{\theta}\right)-\pi_{1} k^{s}}-\left(\lambda^{f+}-1\right) \geq 0 \\
& \Lambda^{f} \equiv \frac{\frac{\lambda^{f+}-1}{\frac{(1+\mu) \pi_{1} k^{s}-\gamma-}{1+r}}-\left(\lambda^{f+}-1\right)}{\frac{(1+\gamma)\left(1+\frac{\gamma}{\theta}\right)-\pi_{1} k^{s}}{1-\lambda^{f-}}}<\frac{k^{s}-k^{0}}{k^{0}-k^{n}},
\end{aligned}
$$

where

$$
\begin{aligned}
& \lambda^{f+}=1+\frac{\left(1+r^{s}\right)(1-\gamma)+\frac{\pi_{1} \theta k^{s}}{1+\gamma}-1+\sqrt{\left[\left(1+r^{s}\right)(1-\gamma)+\frac{\pi_{1} \theta k^{s}}{1+\gamma}-1\right]^{2}+4 \frac{\pi_{1} \theta k^{s}}{1+\gamma}}}{2} \text { and } \\
& \lambda^{f-}=1+\frac{\left(1+r^{s}\right)(1-\gamma)+\frac{\pi_{1} \theta k^{s}}{1+\gamma}-1-\sqrt{\left[\left(1+r^{s}\right)(1-\gamma)+\frac{\pi_{1} \theta k^{s}}{1+\gamma}-1\right]^{2}+4 \frac{\pi_{1} \theta k^{s}}{1+\gamma}}}{2} .
\end{aligned}
$$

We can rewrite $\Lambda^{f}$ as: 


$$
\Lambda^{f}=1+\frac{(1+\mu) \pi_{1} k^{s}-\gamma-\frac{r}{1+r}}{(1+\gamma)\left(1+\frac{\gamma}{\theta}\right)-\pi_{1} k^{s}} \frac{\lambda^{-}}{\lambda^{+}-1-\frac{(1+\mu) \pi_{1} k^{s}-\gamma-\frac{r}{1+r}}{(1+\gamma)\left(1+\frac{\gamma}{\theta}\right)-\pi_{1} k^{s}}} .
$$

We have

$$
\lim _{\theta \rightarrow 0} \Psi^{f}<0
$$

so that no transition is possible for too large adjustment costs because the slope of the unstable arm of the normal steady state goes to $+\infty$ while the slope of the $\widehat{\Xi}_{t}=-\Xi^{s}$ tends to a finite positive limit.

Similarly

$$
\lim _{\theta \rightarrow+\infty} \Psi^{f}=-\infty
$$

so that no transition is possible because the unstable arm of the normal steady state is too steep (the slope of which tends to a finite strictly positive limit) and overshoots the $\widehat{\Xi_{t}}=-\Xi^{s}$ line (the slope of which tends to 0 ).

Therefore, a transition can only occur for intermediate adjustment costs.

Let us define the Assumption 10 as requiring that the two conditions for a transition be satisfied.

Assumption 10: $\quad \Psi^{f}(\theta)>0$ and $\Lambda^{f}(\theta)<\frac{k^{s}-k^{0}}{k^{0}-k^{n}}$

We have proved the following propositions.

\section{Proposition 12 (Multiple Steady States)}

If Assumptions 7, 8 and 9 are satisfied, the economy has two non-degenerate steady states, $k^{n}$ and $k^{s}$, with:

$$
k^{n}=\frac{\pi_{0}-\left(r+\frac{\delta}{s_{r}}\right)}{\pi_{1}}<k^{o}<k^{s}=\frac{\pi_{0}-\left(r+\frac{\delta}{s_{r}}\right)}{\pi_{1}} .
$$

\section{Proposition 13 (Multiple Equilibria and Speculative Growth)}

If Assumptions 7, 8, 9 and 10 hold, there is a speculative growth path that takes the economy from $k^{n}$ to $k^{s}$. Along that path, $\hat{q}_{t}>0$ 


\section{References}

[1] Abel, A.B., N.G. Mankiw, L. H. Summers and R. J. Zeckhauser (1989): “Assessing Dynamic Efficiency: Theory and Evidence," Review of Economic Studies, 56, 1-20.

[2] Beaudry, P and Franck Portier, (2003), "Stock Prices, News and Economic Fluctuations," Mimeo UBC.

[3] Benhabib, J. and R.E.A. Farmer, "Indeterminancy and Sunspots in Macroeconomics," in Hanbook of Macroeconomics ed by J.B. Taylor and M. Woodford, Elsevier Science B.V., pp. 388-448.

[4] Carroll, Christopher D., and David N. Weil (1994): "Saving and Growth: A Reinterpretation," Carnegie-Rochester Conference Series on Public policy, 40, 133-192.

[5] Cecchetti, Stephen G., Hans Genberg, John Lipsky and Sushil B. Wadhwani (2000): Asset Prices and Central Bank Policy, Geneva Reports on the World Economy 2, London: Center for Economic Policy Research.

[6] Christiano, L and Jonal D. M. Fisher (2003) "Stock Market and Investment Goods Prices: Implications for Macroeconomics," NBER Wp \#10031.

[7] Diamond, Peter (1965): "National Debt in a Neoclassical Growth Model," American Economic Review, 55, 1126-1150.

[8] Gavin, M., R. Hausmann, E. Talvi (1997): "Saving Behavior in Latin America: Overview and Policy Issues," IADB Wp \#346, May.

[9] Glassman, Jeremy and Kevin. A. Hassett (1999): "Dow 36,000: The New Strategy for Profiting From the Coming Rise in the Stock Market," Three Rivers Press, New-York.

[10] Greenwood, Jeremy, and Boyan Jovanovic (1999): "The Information-Technology Revolution and the Stock Market," American Economic Review (Papers and Proceedings), $89(2), 116-122$.

[11] Grossman, G., and N. Yanagawa (1993): "Asset Bubbles and Endogenous Growth," Journal of Monetary Economics, 31, 3-19.

[12] Hobijn, Bart, and Boyan Jovanovic (2001): "The Information-Technology Revolution and the Stock Market: Evidence," American Economic Review, 91(5), 1203-1220. 
[13] International Monetary Fund (2000): World Economic Outlook - Asset Prices and the Business Cycle, Washington: International Monetary Fund.

[14] Jaimovich, N (2003), "Firm Dynamics, Markup Variations, and the Business Cycle," Mimeo, Northwestern University.

[15] Kindleberger, Charles P., (1989): Manias, Panics, and Crashes, (revised edition) Basic Books Inc., Harper Collins, USA.

[16] King, I., and D. Ferguson (1993): "Dynamic Inefficiency, Endogenous Growth and Ponzi Games," Journal of Monetary Economics, 79-104.

[17] Kiyotaki, N. and J. Moore (1997): "Credit Cyles," Journal of Political Economy, 105 (2), 211-248.

[18] Krugman, P., (1991), "History versus Expectations," Quarterly Journal of Economics, 106, 651-667.

[19] Murphy, K, A. Shleifer, R. Vishny (1989), "A Building Blocks of Market Clearing Business Cycle Models," NBER Macroeconomics Annual.

[20] Olivier, Jacques (2000): "Growth-Enhancing Bubbles," International Economic Review, 41(1), 133-151.

[21] Rappoport, P. and E.N. White (1993): "Was there a Bubble in the 1929 Stock Market?" The Journal of Economic History 53-3, September, 549-574.

[22] Saint-Paul, Gilles (1992): "Fiscal Policy in an Endogenous Growth Model," European Economic Review, 36, 763-781.

[23] Shiller, Robert J. (2000): Irrational Exuberance, Princeton: Princeton University Press.

[24] Tirole, Jean (1985): "Asset Bubbles and Overlapping Generations," Econometrica, 53(6), 1499-1528.

[25] Ventura, Jaume (2001): "A Portfolio View of the U.S. Current Account Deficit," Brookings Papers on Economic Activity,1, 241-253.

[26] Ventura, Jaume (2003): "Economic Growth with Bubbles," Mimeo CREI.

[27] Vissing-Jorgensen, Annette (1999): "Limited Stock Market Participation and the Equity Premium Puzzle," Ph.D dissertation, MIT. 
[28] Woodford, Michael (1991): "Public Debt as Private Liquidity," American Economic Review, 80(2), 382-388. 